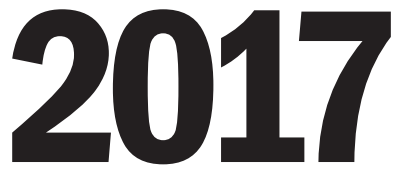

volume $14 \mid$ issue 1

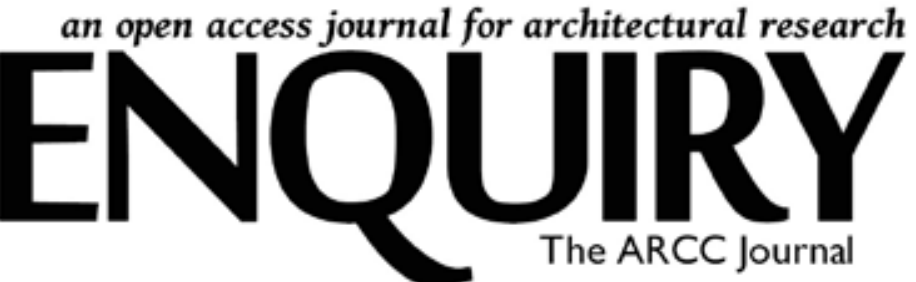

The ARCC Journal

\title{
Land Use and Transport Mode choices: Space Syntax Analysis of American Cities
}

\author{
Girmay Kifle Berhie and Saif Haq
}

\begin{abstract}
Natural movement theory from space syntax literature postulates that configuration of the urban grid is an important generator of aggregate patterns of movement in urban areas (Hillier et al. 1993). In addition, movement economy theory asserts that retail and commercial activities migrate to configurationally hotspot locations to take advantage of the economic opportunities created by movement (Hillier 1996). These concentrations of retail and commercial activities are also the work places for a good number of people and, in turn, will influence the choices of residential locations. Since journey-distance and time are two very important factors influencing transport mode choice, (Plaut 2005; Wardman, Tight, and Page 2007; Pucher and Dijkstra 2003; Schwanen and Mokhtarian 2005),this paper hypothesized that the locations of retails and commercial areas as understood by their space syntax derived configurational index, will first affect the choices of residential locations and then influence choices of commuting mode.
\end{abstract}

This hypothesis is tested in four US cities of Boston, Pittsburgh, Lubbock, and Salt Lake City using data collected from online open source database of the respective cities and US census bureau. Space Syntax topological and angular analyses of CAD drawn axial lines and street centerlines extracted from GIS maps are performed for all cities. ArcGIS spatial analysis tools are applied to combine land use, socio-economic, demographic, transportation and Space Syntax variables to the scale

\section{Permissions and copyright}

Authors retain copyright and grant the journal right of first publication with the work simultaneously licensed under a Creative Commons Attribution License that allows others to share the work with an acknowledgement of the work's authorship and initial publication in this journal (Attribution-ShareAlike).

Creative Commons Attribution 3.0 Unported (CC BY 3.0)

You are free to: Share - copy and redistribute the material in any medium or format. Adapt — remix, transform, and build upon the material for any purpose, even commercially. The licensor cannot revoke these freedoms as long as you follow the license terms.

Under the following terms: Attribution - You must give appropriate credit, provide a link to the license, and indicate if changes were made. You may do so in any reasonable manner, but not in any way that suggests the licensor endorses you or your use.

No additional restrictions - You may not apply legal terms or technological measures that legally restrict others from doing anything the license permits. Analysis of American Cities" Enquiry 14 (1): 1-22.. of census block-groups that was selected as the study unit. Multiple regression analyses are carried out to identify relevant and significant variables explaining each mode of transport. The findings indicate that Space Syntax variables play an important role in explaining choice of commuting mode. In addition, several linear regression analyses are performed to examine the land use and transport mode choice in the context of street configuration. The results indicate that commercial and retail concentration were positively correlated with integration cores. Following general trend of space syntax findings, commuters tend to live at configurationally segregated areas while walkers and bicycle riders tend to live in configurationally integrated areas where commercial and retail activities are concentrated. Regarding the differences of layout types, the results of comparative analysis between gridded and nongridded cities indicates that closeness variable called 'integration' and betweenness variable called 'choice' are relevant to explain walking and driving modes in non-gridded and gridded cities respectively.

\section{KEYWORDS}

Space Syntax, Sustainability, Land Use, Street Network Design

\section{INTRODUCTION}

Air quality dramatically declines in metropolitan regions where the land development pattern overwhelmingly favors the automobile (Levine and Frank 2006). Consequently, the choice of transport mode has become one of the prime foci in study of environmental quality. As policy makers are recognizing the need for alternatives to motor vehicle journeys to mitigate environmental impacts, research on the factors that affect choice of non-motorized transportation ${ }^{1}$ (NMT) are gaining attention. This exploratory research is an attempt to understand if indeed street configuration plays a role in mode choice, and if so what might be the contribution of Space Syntax.

Space Syntax is a set of theories and techniques for the analysis of spatial configurations conceived by Bill Hillier and colleagues at the Bartlett, University College London in the 1980s. Over the past three decades, space syntax theory has provided important computational support

1 Only walking and cycling are considered as non-motorized transportation in this paper 
for the development of spatial morphological studies, particularly for the analysis of urban systems. Studies indicate that space syntax has produced positive results in predicting socio economic pattern of the built environment. It has been widely used for modelling pedestrian and vehicular movements (Hillier et al. 1993), crime analysis (Jones and Fanek 1997; Nubani and Wineman 2005), traffic pollution control (Penn and Croxford 1997), and way finding processes (J. Peponis, Zimring, and Kyung Choi 1990) including cognition (Haq 2003). Space syntax provides a configurational description of an urban structure and attempts to explain human behaviors and social activities. However, what is not yet sufficiently studied is whether street configuration has meaningful impact on choices of travel mode and preferences of residential locations.

\subsection{Background}

Transportation and land use patterns of urban areas are inextricably intertwined as one affects the other. Travelers are expected to weigh the comparative travel times, costs, and other attributes of transportation modes when deciding how to get between point $A$ and point $B$. Choices of residential location with respect to work place is one of the key factors that influence the decision how to get to work (Cervero 2002). This study recognizes the underlying discourse on the question whether decisions of residential location is affected by transportation mode or mode choice is influenced by the location of residence in relation to the work place. People may respond differently to the location-transportation relationship question depending on individual/ household characteristics. For instance, for higher-income families housing factors of neighborhood quality, safety, and social class might be more important than distance to work or CBD (conventional location of employment and business concentrations). In contrast, lower income households may prioritize transportation cost (Giuliano 2004). At the same time, higher-income households are more sensitive to travel time than lower-income families (Giuliano 2004). Newman and Kenworthy (1996) argue that the primary factor that has shaped cities over time is that people do not want to travel more than half an hour to major urban destinations. This prompted transport technologies to evolve towards greater speed and freedom of reaching destinations of longer distance, which in turn, shaped the contemporary urban form and travel behavior (Newman and Kenworthy 1996). The emergence of high-speed expressways made possible for people to live away from city centers and yet not be susceptible to a long travel time.

In this study, the locations of employment centers in relation to the residential locations is an important factor that has been taken into account. Minimizing travel distance to work is one of the several factors that households consider in their decisions of optimum residential locations. Given a fixed location of employment, we can predict an average commuting length. Therefore, study of employment patterns in relation to residential locations is imperative to understand travel behavior particularly travel mode choice.

The theory of 'natural movement' postulates that configuration of the urban grid is an important generator of aggregate patterns of movement in urban areas (Hillier et al. 1993). Retail and commercial land uses locate themselves at these configurationally hotspot locations to take advantage of the economic opportunities created by movement (Hillier 1996). This study realizes that these retail and commercial areas are also work places for a good number of people. Since distance of residential location from work is an important factor affecting the choices of transportation mode, this paper aims to investigate the preferences of walkers on residential locations as opposed to car commuters. Additionally, the study will examine what relationships might exist between tenure type, household type, and travel mode choice. In addition, space syntax variables are examined for a role in predicting transportation mode choice, especially when compared to those previously identified variables by transportation researchers; i.e. spatial, social, and economic factors. Finally, the paper attempts to unveil the difference between configuration properties of gridded and non-gridded cities in the context of transportation mode choice.

\subsection{Configurational Accessibility}

Configuration takes into account the average accessibility of all points to all other points in the system. Accessibility is defined as the ease of movement between two points. Accessibility between two urban places can be computed based on two different concepts namely 'shortest path' and 'simplest path'. Shortest distance between two points is calculated based on metric distance. On the contrary, simplest route selection does not consider metric distance but instead depends on cognitively

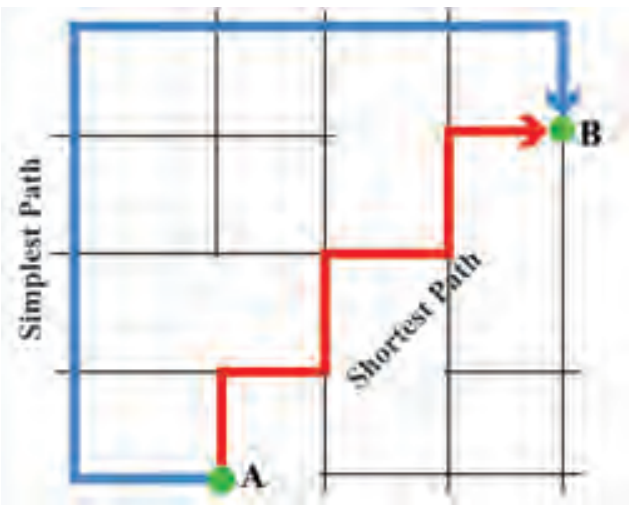

Figure 1. Illustration of shortest vs. simplest paths between two pints

understood path (Courtat, Douady, and Gloaguen 2011)

Space Syntax accessibility measures the ease of movement based on the concept of simplest route. Simplest route between two points determines the path connecting the points with minimum number of turns. This theory argues that the perception of location accessibility or remoteness based on choice of paths depends on people's wayfinding skills (Haq 2003) and mental conceptualizations of the environment (Charalambous and Mavridou 2012). It is suggested that the most accessible locations are not necessarily those closest to all other locations in terms of metric distances but rather those closest in terms of topological turns (Hillier et al. 2007). One of the most important configuration accessibility measure is integration. This value of a space is a function of the mean number of spaces and changes needed in order to reach all other spaces in that system. Integrated urban space is expected to attract more movement than segregated spaces, which in turn affects land use pattern (Hillier et al. 1993).

In Space Syntax analysis, there are few key terms need to be clarified. These are axial lines, spatial accessibility and spatial choice. Spaces are represented by straight lines called 'axial lines' drawn between two points (figure 2). These lines are based on how far an observer can have an uninterrupted impression of visibility or permeability along the street (Hillier \& Hanson, 1984; John Peponis et. al, 1989). The axial map is the representation of urban space as a matrix of the 'longest and fewest' lines in the system (Hillier 1999b) and is the basis of layout analysis. Each axial line represents a unit of real world space which is usually street or 


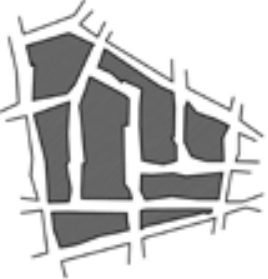

a) Urban block map

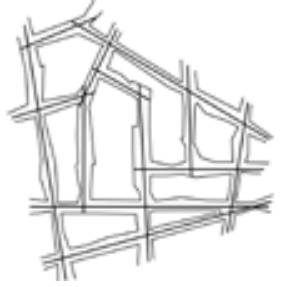

b) Axial lines drawn along streets

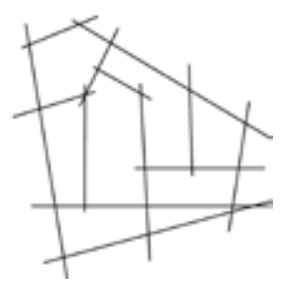

c) Axial map
Figure 2. Illustration how axial line are extracted

part of it. Axial lines are used in space syntax to understand connections between spaces that make up an urban morphology.

Accessibility of a space (in this case street) is determined by its relative distance to all other spaces. These spatial relationships are measured through the concepts of 'integration' and 'choice' of each street (axial line). The measure of integration of a space is determined based on the term 'depth', which calculates number of spaces and changes needed in order to reach all other spaces in the system. From a reverse point of view, this is also a measure of 'closeness'; that is, how close a space is, on an average, from all other spaces in that network. Spaces with lower average depth to all other spaces in a street network are said to be 'integrated', and those spaces with higher average depth are 'segregated'. Integrated streets in a system are assumed to be accessible from all other streets. Therefore, they are considered more attractive destinations of movement than segregated ones simply as a result of their configurational position in the network. Thus, integration is said to be a measure of 'to movement' (Hillier et al. 1993). In other words, integrated areas would be good candidate for destination of journeys.

Choice measures the state of betweenness (Varoudis et al. 2013; Narayanan 2005; L. C. Freeman 1977; L. Freeman, Borgatti, and White 1991) i.e. the extent of space being placed at the shortest paths connecting spaces in the system. In other words, choice measures how much movement is likely to pass through a space on trips between origin and destination spaces. The value of choice of a street segment is determined by the total numbers of shortest paths between pairs of origins and destinations using that segment of spaces. Choice is a measure of 'through movement' (passing by movement) since it is about the spaces between the origin and destination. Higher choice value of a street segment means more movement would be passing through that segment of the street. In other words, there would be busier traffic or pedestrians. Integration and choice measure are calculated on two concepts of distances; topological and angular. Topological parameter depends on the total number of turns between point $A$ and Point $B$. Angular parameter is calculated based on the total sum of angular turns between origin and destination points.

\subsection{Configurational Centrality}

Centrality has been studied in many branches of urban research, including economic geography, regional analysis, and transportation planning. In most cases, centrality has been dealt with as means of measuring the spatial interactions of activities. The most common and essential interpretation of centrality is based on the notion that a more central location is a place closer to all others (Porta et al. 2009).

While urban centrality is defined as concentration of activities; configurational centrality is a location of core integration values. These locations of higher integration values are expected to attract a higher number of movement. Movement seeking activities will follow movement-rich locations. Therefore, the creation of centers becomes a process of interaction between movement seeking activities and movement itself. Hillier (1999) asserts that centrality is a dynamic phenomenon and one should understand centrality as a process rather than to describe it as a static state because centers not only expand or contract, but may also shift their focus over time (Hillier 1999a). Configuration of street network are the driving factor for the creation and consolidation of activity centers (live centers).

While defining the relationship between socioeconomic and spatial laws, Hillier (1999) claims that even though socioeconomic processes drive the creation of spaces of the city, they do not exclusively shape them. Two classical theories namely 'natural movement' and 'movement economy' are at the center of the centrality process, and are described below.

Natural movement theory postulates that the proportion of urban movement is determined by the configuration of street layout. The dynamics of local area of a city is the function of its global structure . The land use change in certain vicinity is predominantly governed by the global spatial configuration. Hillier et al. (1993) asserts that configuration is the primary generator of movement pattern in urban systems. Land use is a by-product of movement and cannot change the configuration but can only have a multiplier effect on the basic pattern of movement established by the configuration. The phenomena that the basic pattern of movement generated by configuration of the urban gird itself is called 'natural movement'.

Movement economy theory on the other hand deals with how movement generated by the spatial configuration of street layout shapes land use pattern. Hillier asserts the land use pattern inherently follow the hidden property of spatial configuration. Some land uses such as retails and commercial activities naturally search and migrate to more integrated streets to take the economic advantage of movement generated by the configuration. The process of attracting uses and multiplying movement has a cyclic nature shaping the land use and centrality patterns of urban areas. Hillier explains that the layout of space first generates movement, and then movement-seeking land uses migrate to movement-rich street segments producing more movement (multiplying movement), which further attracts more retail and other uses. This leads to the adaptation of the local grid to accommodate the greater density and mix of uses. This dynamic process is called the 'movement economy' (Hillier et al. 1993; Hillier 2008; Topçu, Topçu, and Deniz 2007).

\section{METHODOLOGY}

\subsection{Case Study Selection}

In order to examine the question if street configuration plays a role in transportation mode choice, case study analysis was performed on four American cities: Boston (MA), Pittsburgh (PA), Lubbock (TX), and Salt Lake City (UT). The selection of cities was based on one of the objectives of the study, namely understanding the variations and similarities between gridded and non-gridded cities. Therefore, the task was to find two groups of US cities whose street networks represent each form (gridded and non-gridded). However, the characteristics of gridded-ness or nongridded-ness is not a duality. Rather, it is a continuous property where any city may fall at any point in a sliding scale ranging from a perfect grid to perfect organic urban form. After a comprehensive search of maps of several cities, Boston and Pittsburgh were selected to represent nongridded cities; Lubbock and Salt Lake City were selected to represent 


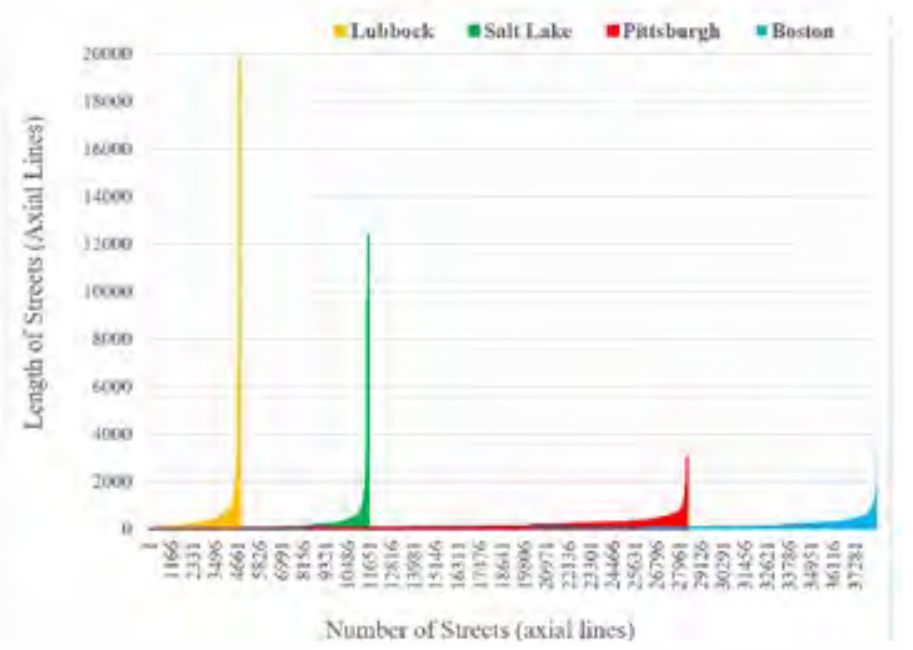

Figure 3. Graph illustrating number of streets sorted by length

gridded cities.

The graph in Figure 3 illustrates the two categorized groups of cities through axial line relationships, clearly showing that both gridded cities fall at the left spectrum of the sliding scale (fewer and longer axial lines) whereas non-gridded cities fall on the right side (more and shorter axial lines). This pattern occurs because a perfectly gridded street network produces long axial lines (i.e. they become unbroken and have maximum length). On the contrary, in an organic street layout system, axial lines are broken into multiple lines as streets are shorter and curved.

\subsection{Data sources}

Two primary data sources for this study were the US census 2010 and GIS open database websites of respective cities. All data related to socioeconomic and demographic characteristics of census jurisdiction (census block group) were gathered from the online database of census bureau website. All Spatial information, such as transit stops, transit routes, and land use (commercial and retails), building figure ground, street network etc. were extracted from free access websites of the respective city GIS data sources.

This study also divided the 2010 US census data on socio-economic, demographic and travel behavior into two categories of data, namely spatial and non-spatial data. Spatial data are locations or geographic features that are stored in a coordinate format, such as buildings, streets, parcels, locations of commercial or retail uses and transit stops of urban areas. Non-spatial data are attributes attached to spatial features. Attributes contain information about geographic features but are not directly referring to spatial concepts, such as the area of buildings and commercial parcels, property value, population density, street density, composition of race and tenure (renters vs homeowners) etc.

\subsubsection{Space Syntax Variables}

Two types of accessibility measures integration (closeness) and choice (betweenness) of Space Syntax analysis were computed using two simplest path distance concepts. The first distance concept is topological distance; it computes both integration and choice values based on the mean number of turns a point needs to get to all other points in the city. The second distance concept is angular distance, which computes integration and choice values based on the mean angular degrees of turn one needs from a point to all other points in a city. Therefore, four space syntax variables were extracted from two measures of accessibility computed using two different concepts of distance as indicated in Table 1 below.

Table 1. Space syntax variables

\begin{tabular}{|l|l|l|}
\cline { 2 - 3 } \multicolumn{1}{c|}{} & \multicolumn{2}{c|}{ Methods } \\
\hline $\begin{array}{l}\text { Measures of } \\
\text { Accessibility }\end{array}$ & Topological & Angular \\
\hline Integration & $\begin{array}{l}\text { Topological } \\
\text { Integration }\end{array}$ & Angular Integration \\
\hline Choice & Topological Choice & Angular Choice \\
\hline
\end{tabular}

\subsection{GIS Spatial Analysis}

The data sources used in this study provides information at different kinds of spatial units. The 2010 Census provides information at the census block-group spatial unit; all other spatial data from the cities' database are available for smaller areas. For example, land use data is available at a parcel level, bus or transit transport stations are available at point level. Information related to buildings is also available at a building level. On the other hand, space syntax (configuration) variables obtained from axial lines represent streets or portions of streets.

This mismatch of units was resolved so the relationship of variables could be tested at the same geographical (spatial) unit. The 'block group' was selected as the unit of the study as it had the strongest relationship when considering translation between scales. The process of spatial translation included various GIS spatial analysis and map overlays.

As discussed in the background (section 1.1), the study began with the assumption that integrated areas attract retails and commercial activities, which become workplaces for a good number of people. These, in turn, have an effect on the choices of residential locations. It is an assumption of this study that people who walk or bicycle to work will choose to stay close to their place of employment because they want to reduce the walking or bicycling distances. Therefore, this study expects to find more walkers and bikers living in integrated areas but not necessarily in the integrated streets themselves. From this point of view, the investigation had to be focused on defined areas of cities rather than streets or axial lines. Space syntax values of linear features were converted to block group through overlaying and aggregation process of spatial analysis in ArcGIS as illustrated in Figure 12.

GIS map overlay analysis identifies the relationship between census block group and axial line location. As indicated in Figure 12b, axial lines with integration value is overlaid on the block-group polygons. This identifies where each segment of axial line belongs to in census block group map. Finally, the average values of integration values of axial line in each block group is computed as displayed in Figure 12c. Comparison of topological integration of axial line and average topological integration of census block group for all cities are illustrated in Figures 13 and 14 . 

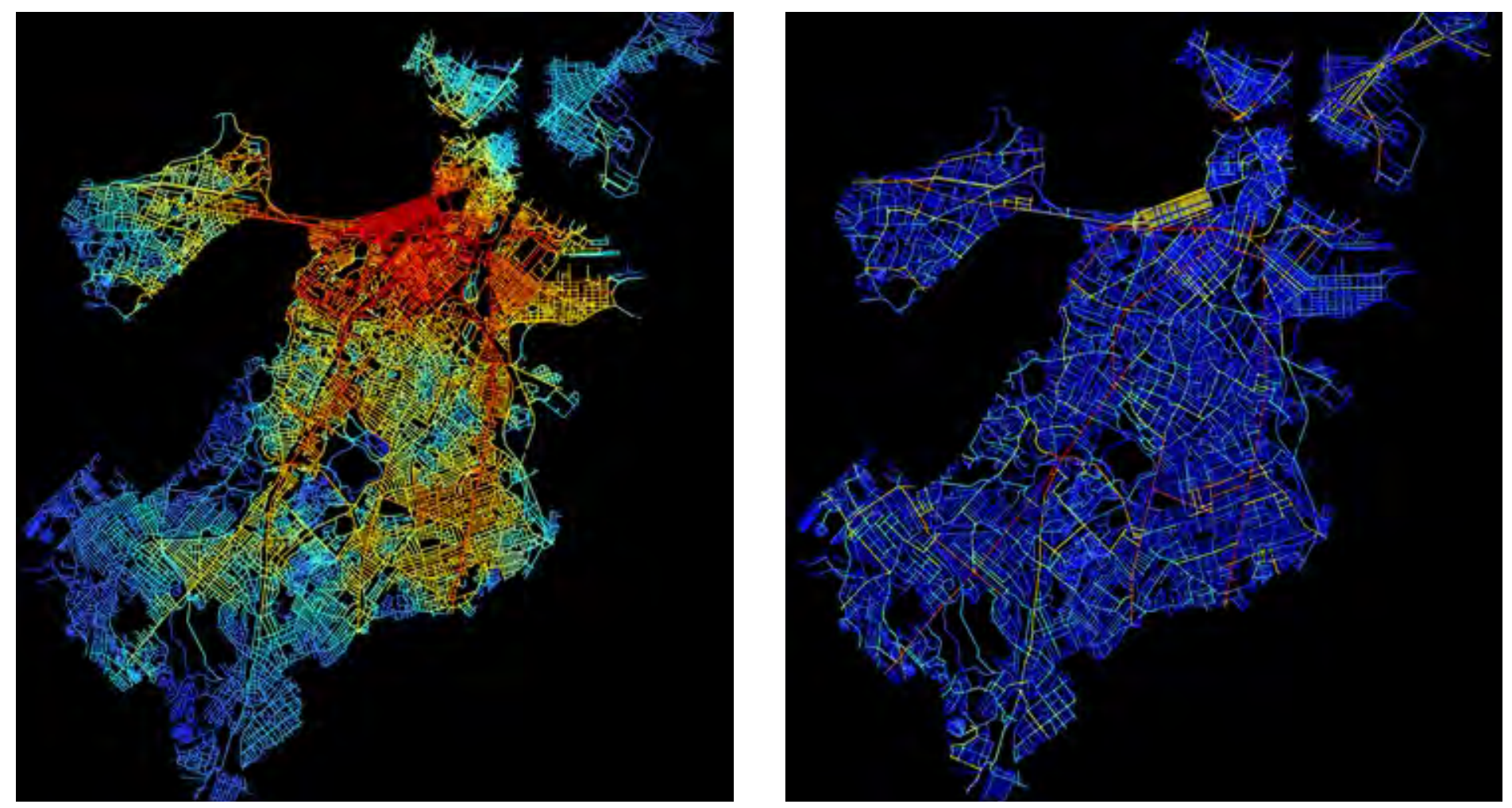

Figure 4. Topological Integration (left), Topological Choice (right) of Boston
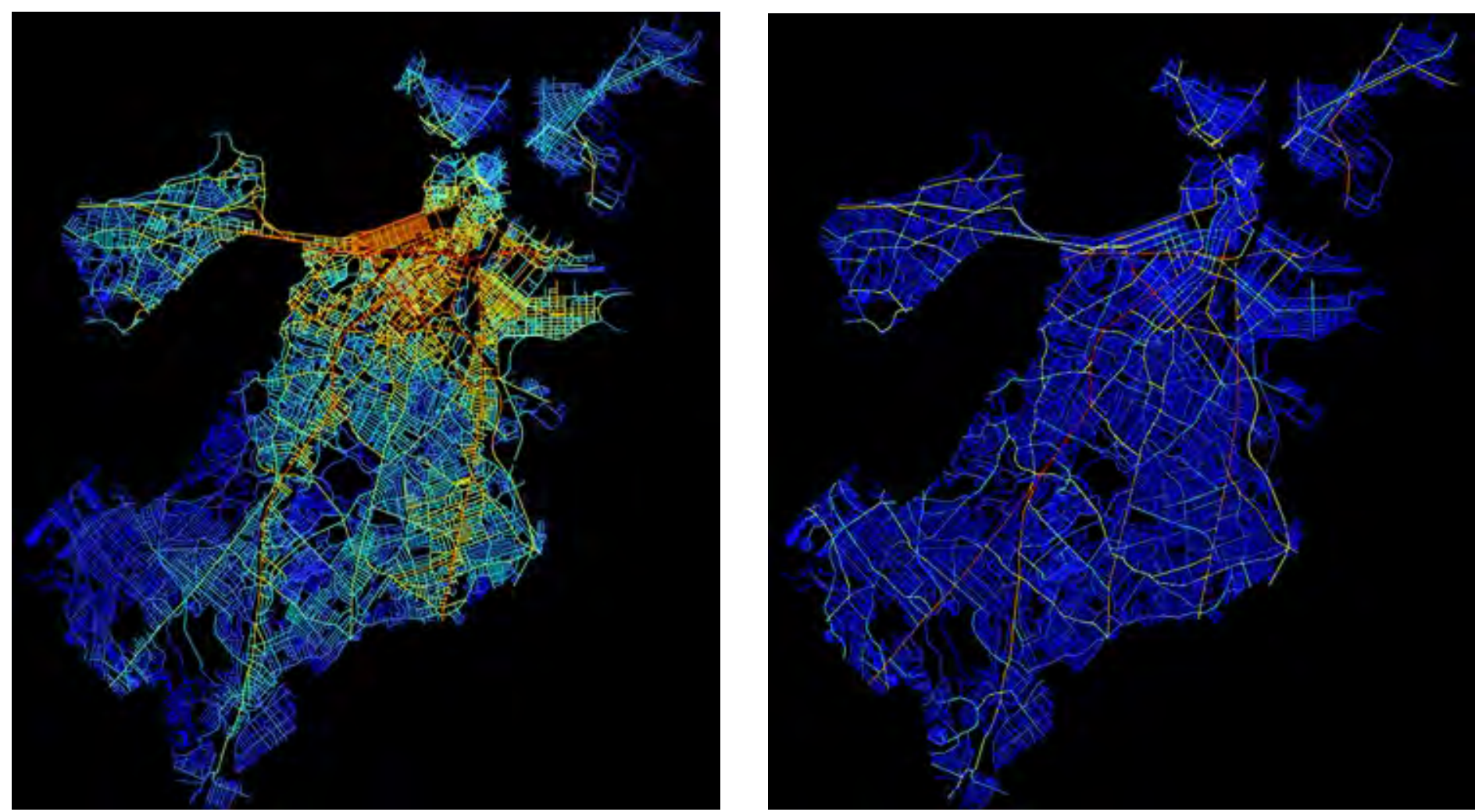

Figure 5. Angular Integration (left), Angular Choice (right) of Boston 

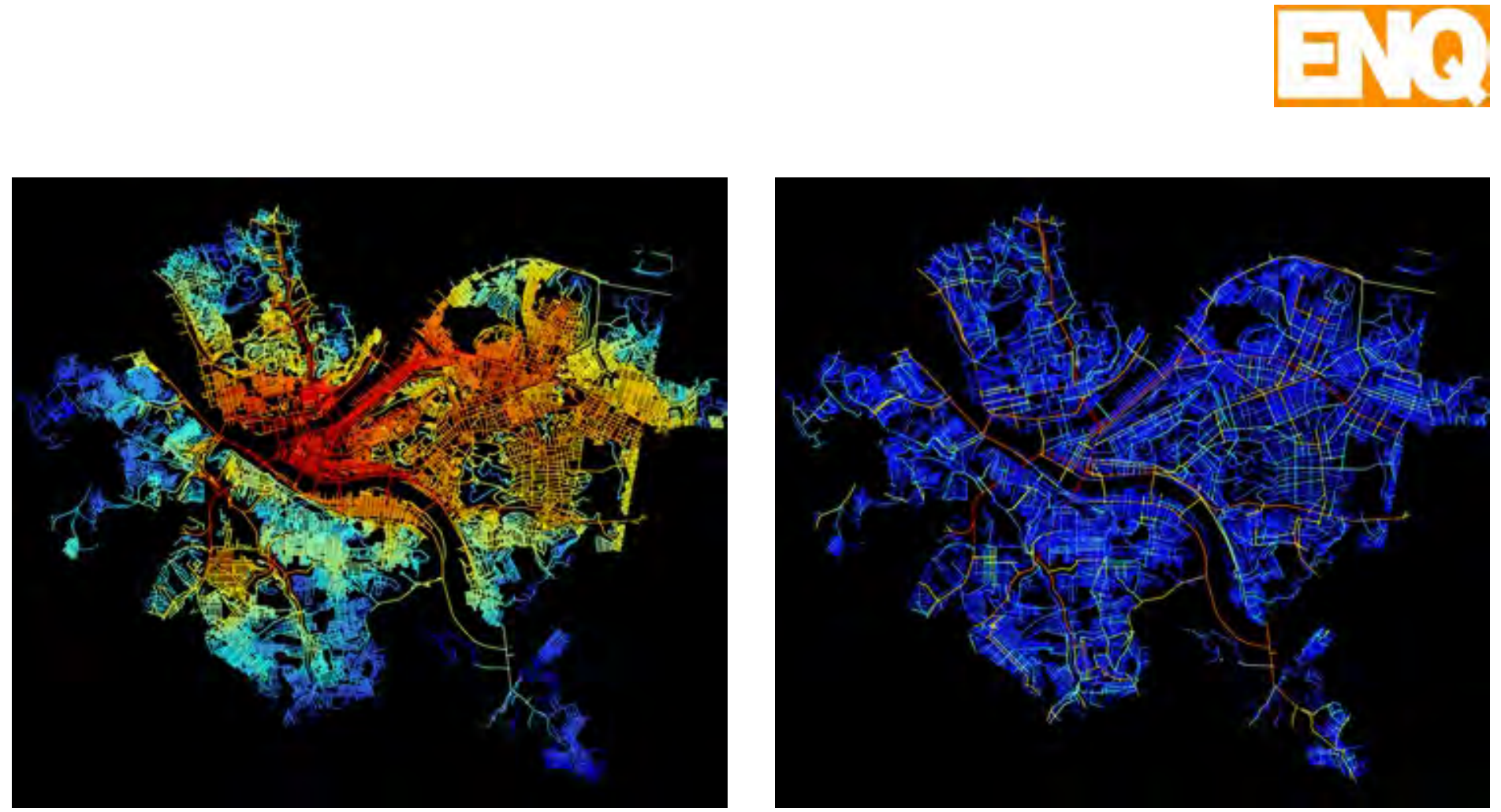

Figure 6. Topological Integration (left), Topological Choice (right) of Pittsburgh
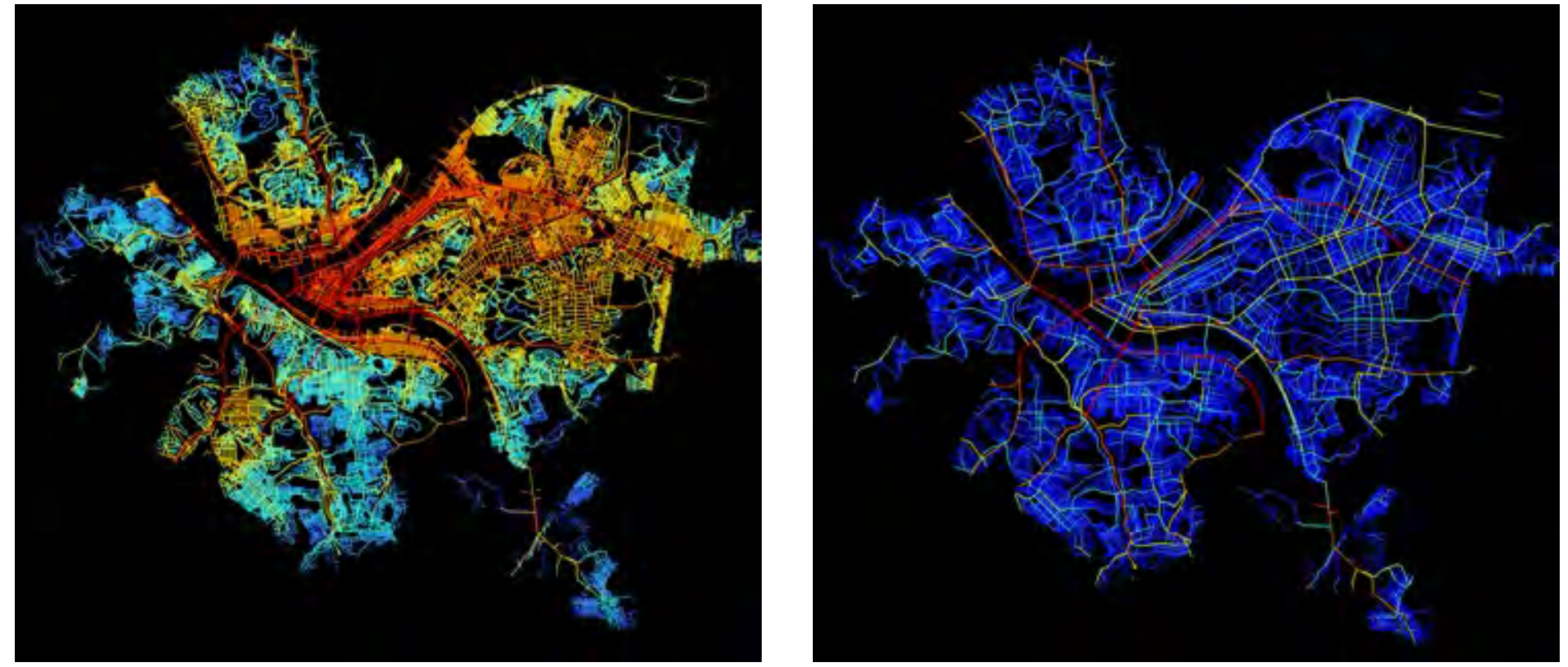

Figure 7. Angular Integration (left), Angular Choice (right) of Pittsburgh 

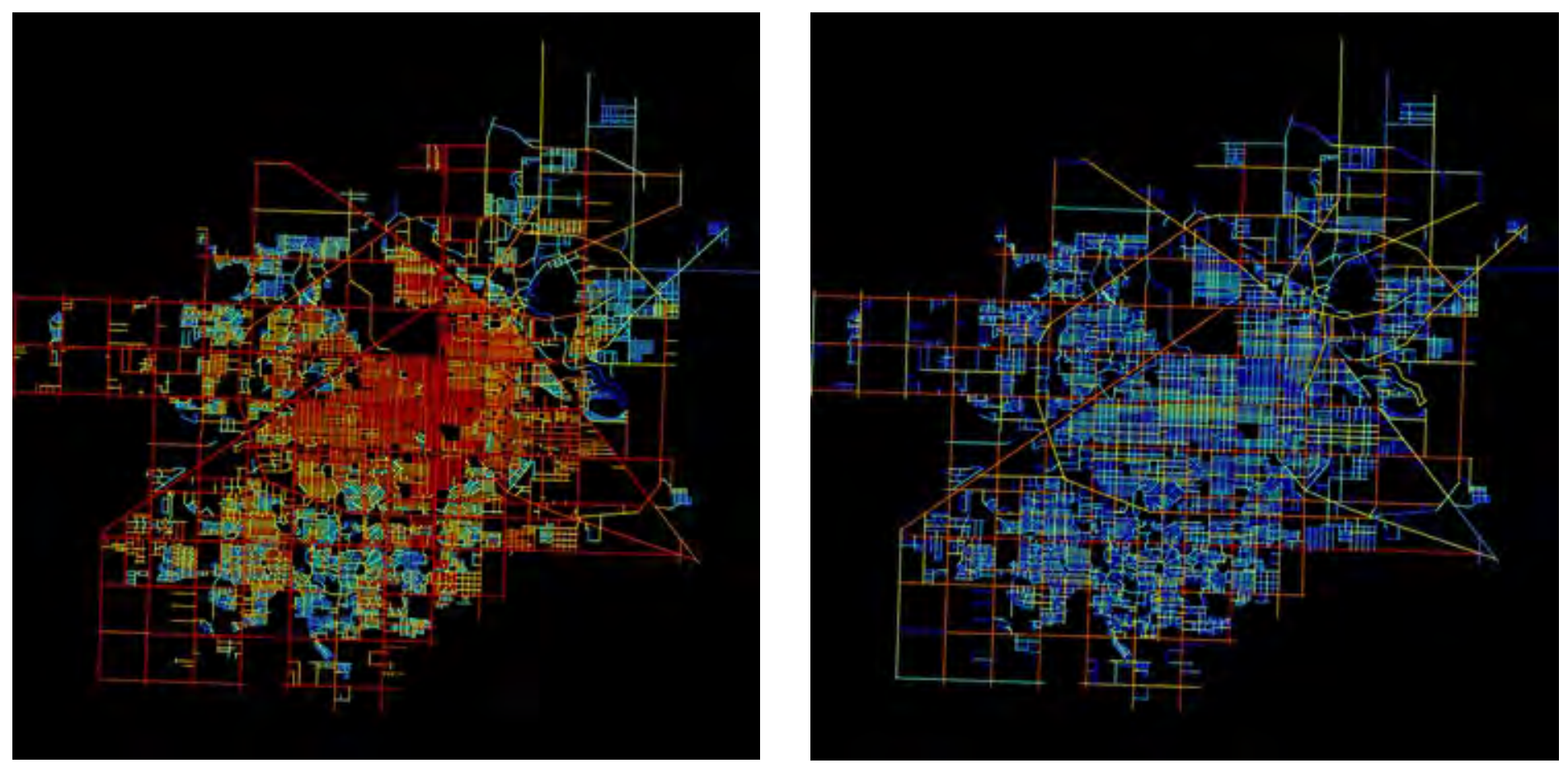

Figure 8. Topological Integration (left), Topological Choice (right) of Lubbock
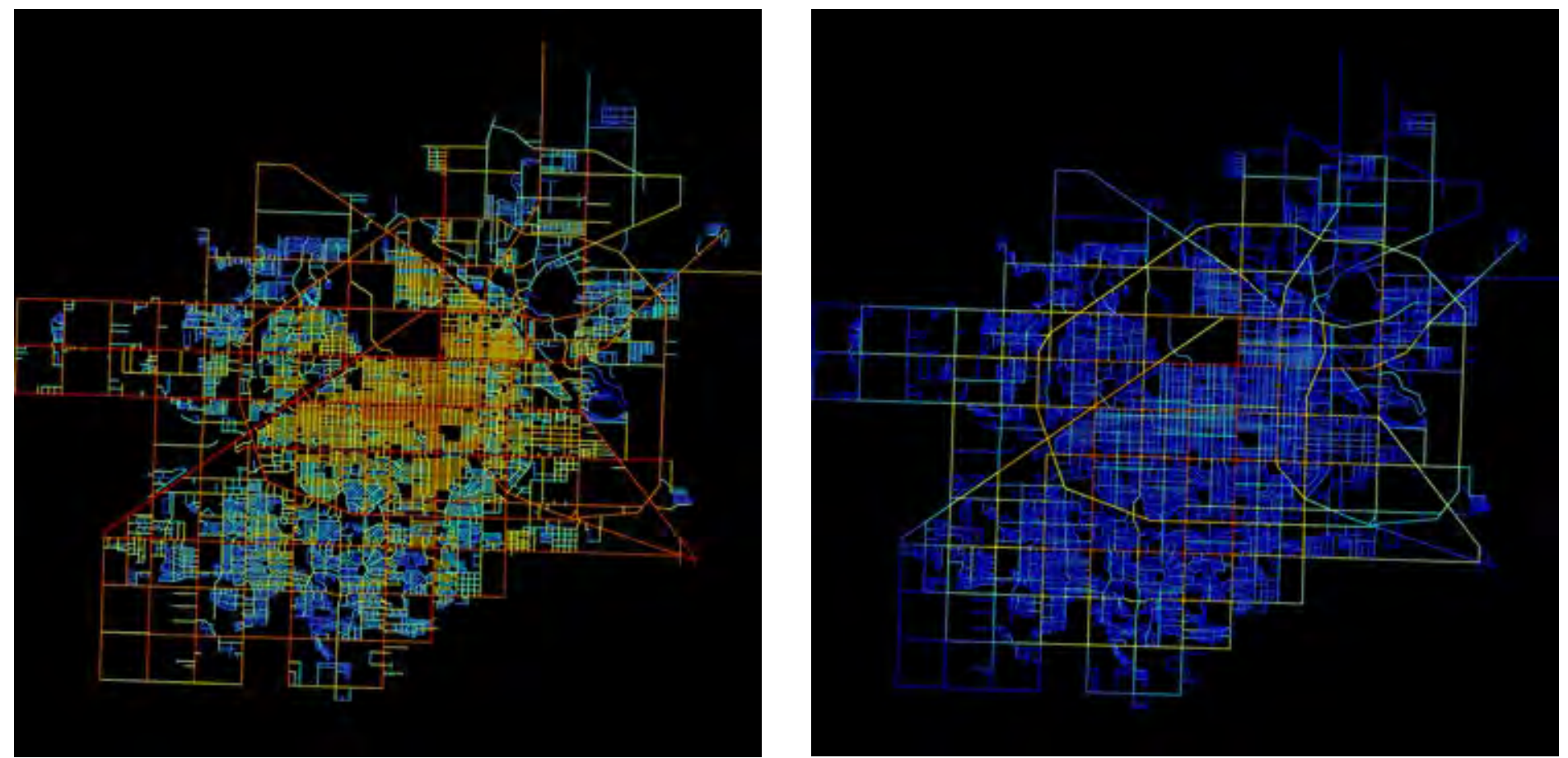

Figure 9. Angular Integration (left), Angular Choice (right) of Lubbock 

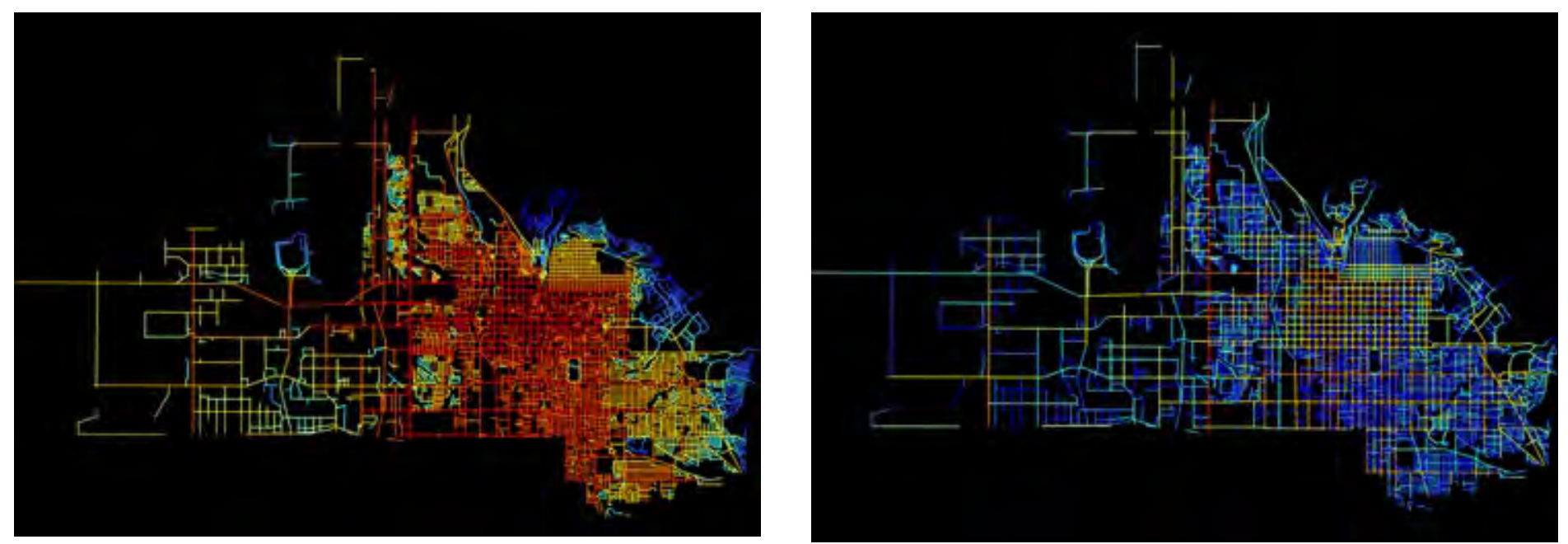

Figure 10. Topological Integration (left), Topological Choice (right) of Salt Lake City
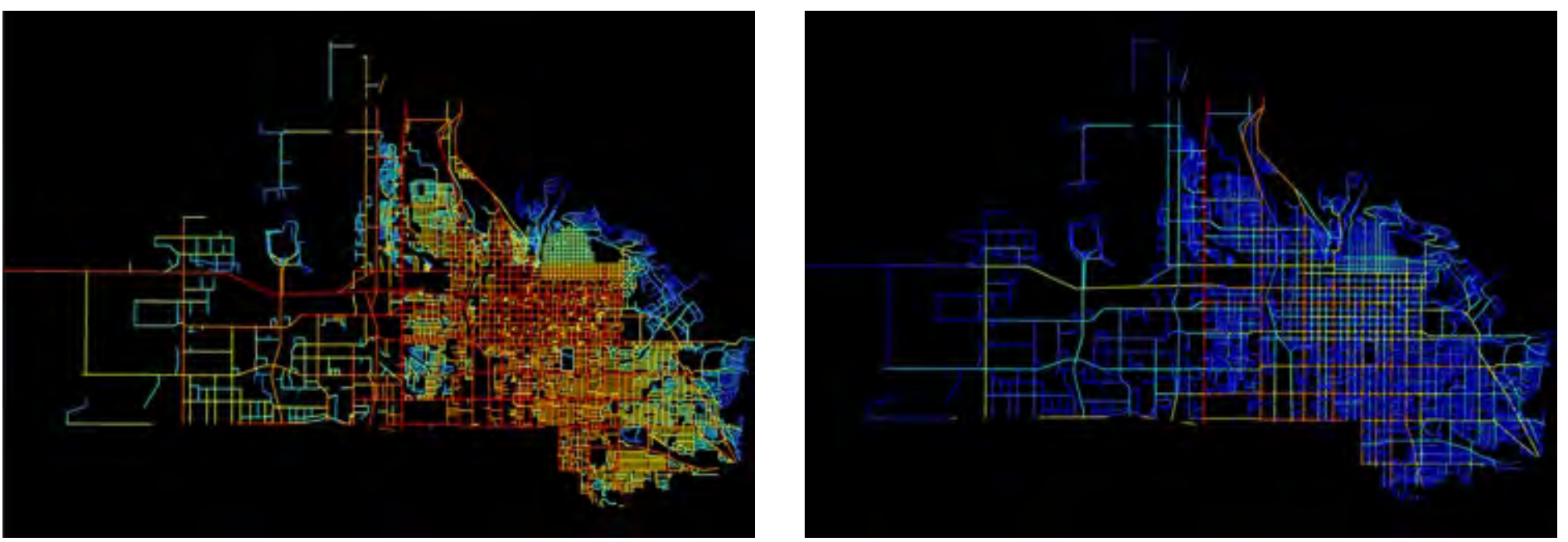

Figure 11. Angular Integration (left), Angular Choice (right) of Salt Lake City

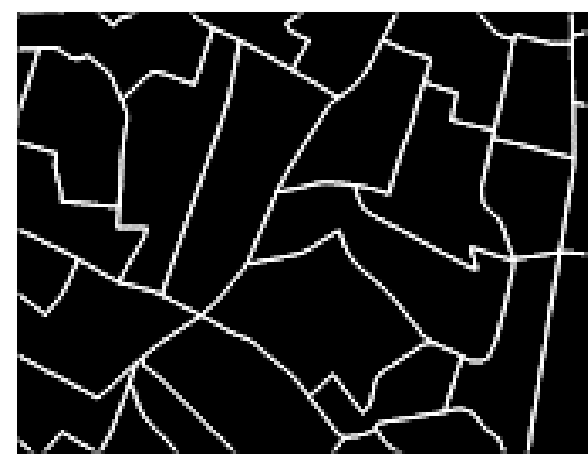

a) Census block group

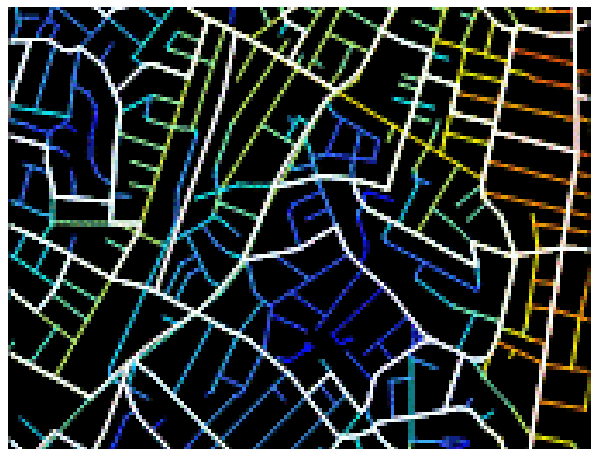

b) Integration overlaid on block groups

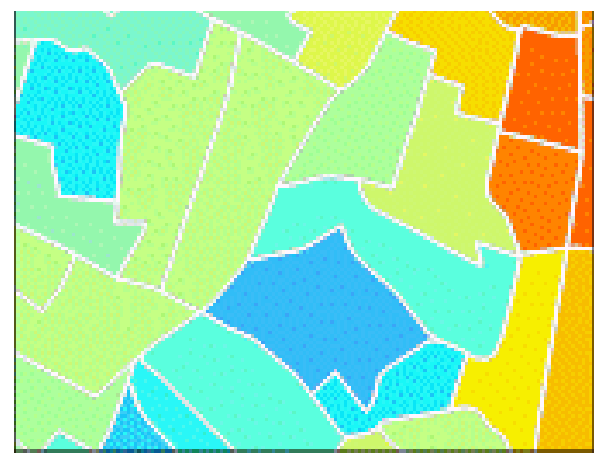

c) Average integration of block groups The colors represent integration values ranging between red indicating most integrated and blue most segregated areas

Figure 12. Procedure of converting configuration values of axial lines to census block-group polygons 


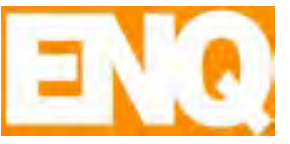

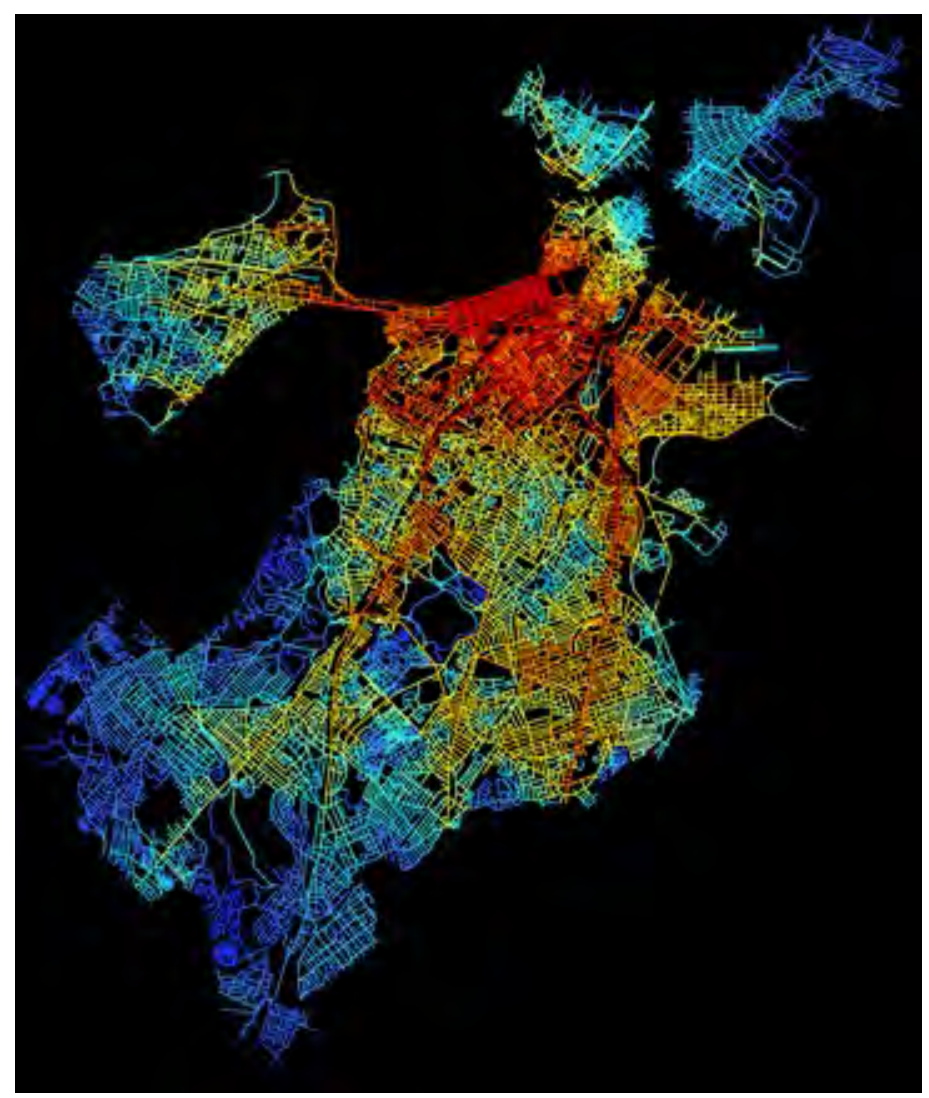

Boston (axial lines)

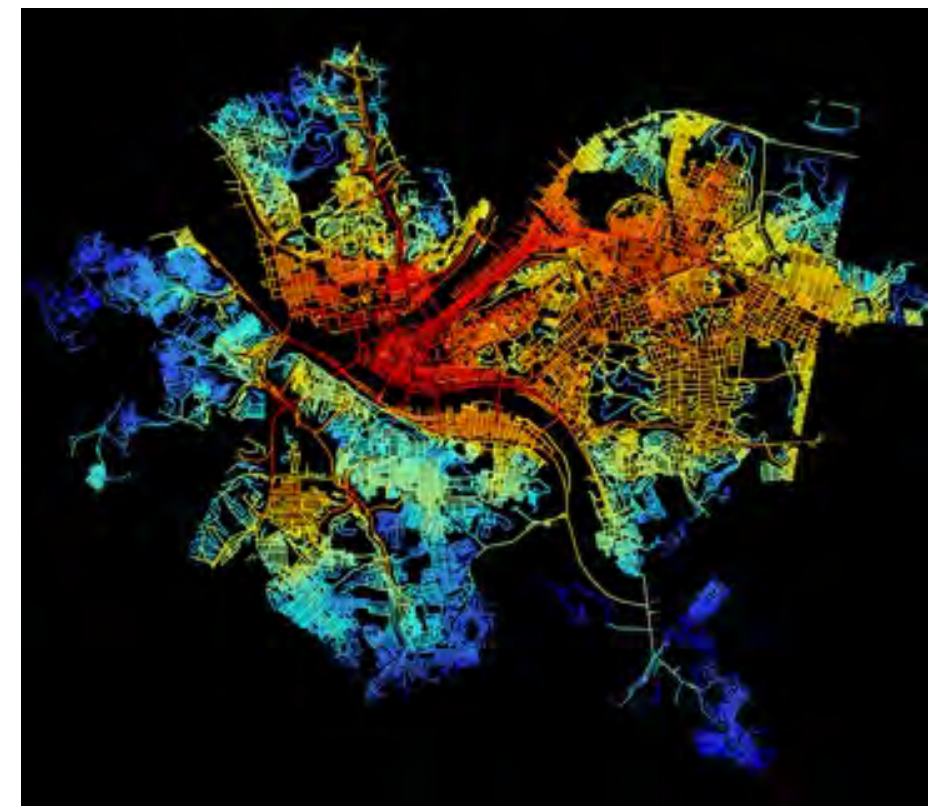

Pittsburgh (axial lines)

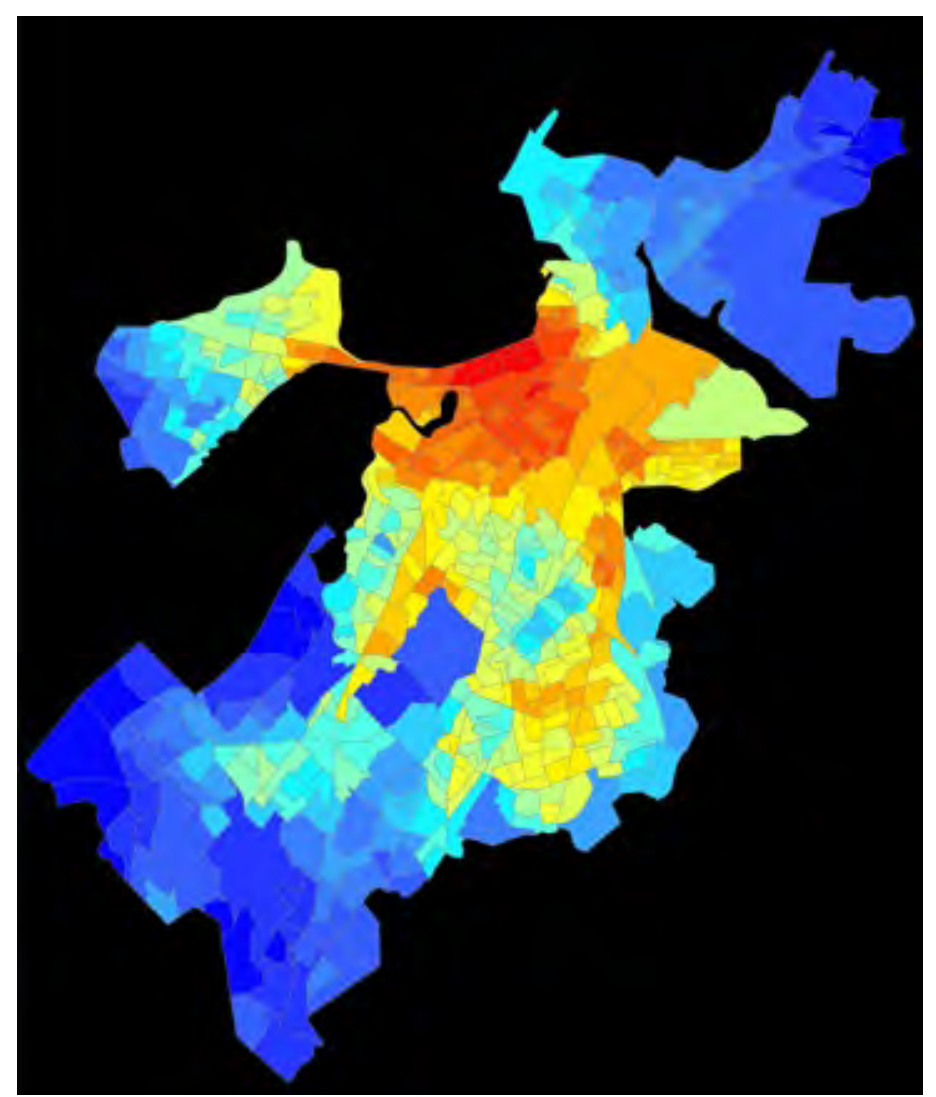

Boston (block groups)

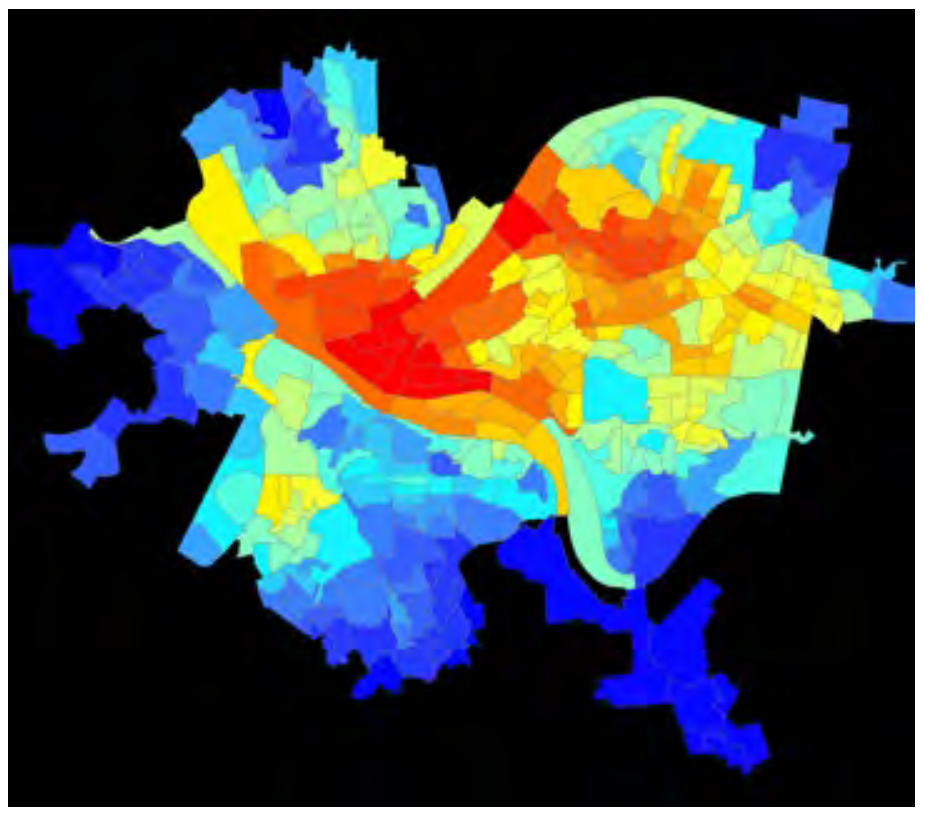

Pittsburgh (axial lines)

Figure 13. Illustration of converting topological integration values of axial map (left) to average integration values of census block groups (right) of non-gridded cities 

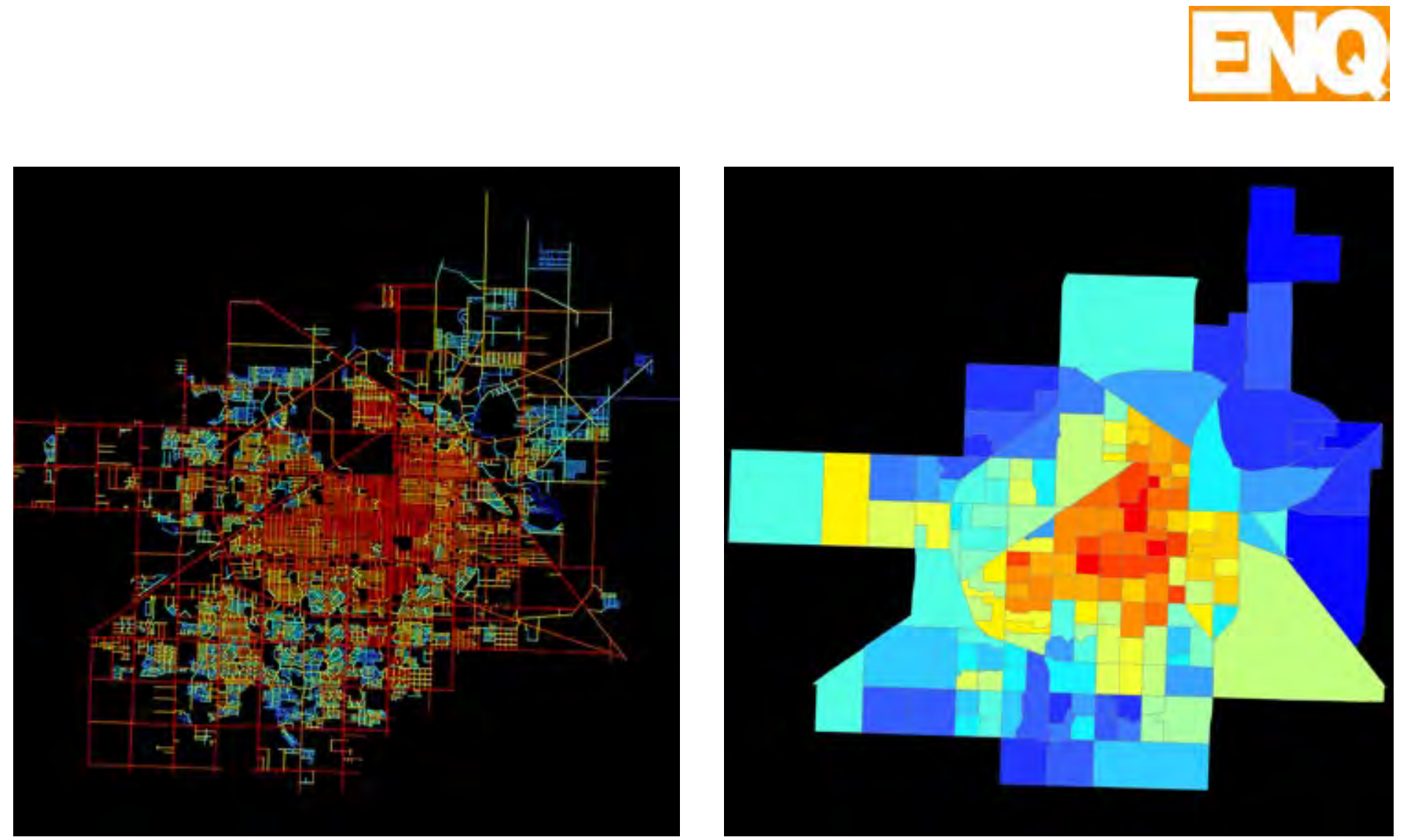

Lubbock (axial lines)

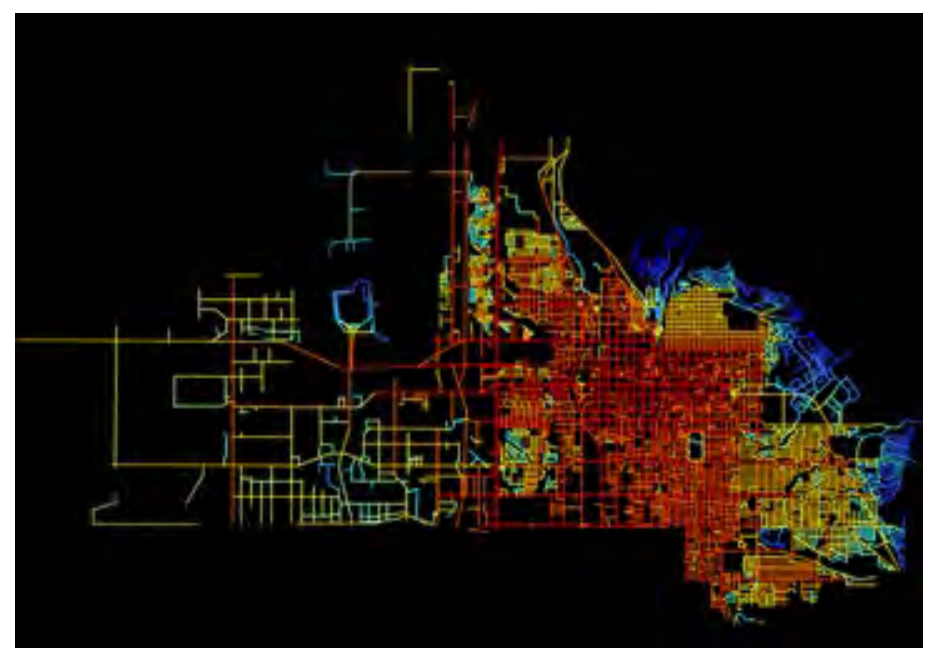

Lubbock (block groups)

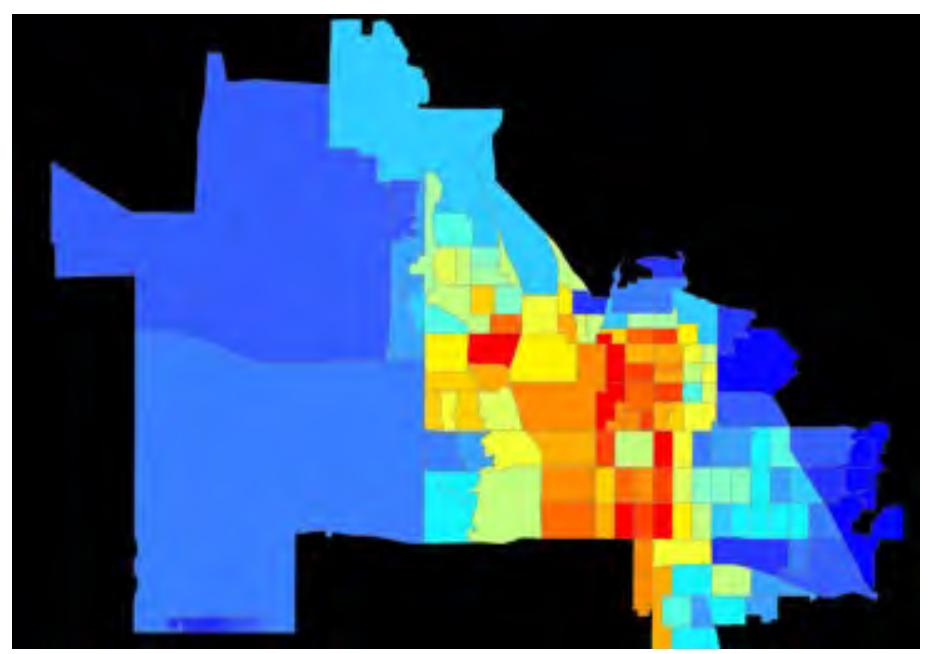

Salt Lake City (axial lines)

Salt Lake City (axial lines)

Figure 14. Illustration of converting topological integration values of axial map (left) to average integration values of census block groups (right) of gridded cities

\subsection{Variables Used}

This exploratory study involves extensive lists of variables to investigate the competitive power of space syntax variables explaining mode choice. In developing models of transport mode choice through multiple linear regression, four dependent variables, and twenty-five independent variables are involved (see table 2 below).

\subsection{Statistical Analysis}

Statistical analysis was carried out using four modes of transportation as dependent variables (i.e. driving, walking, public transport and bicycling by US census bureau). Among the total of twenty-five independent variables, seven are land-use related factors, eleven are related to socio-economic and demographic characteristics, three are transport 
Table 2. List of variables used

\begin{tabular}{|c|c|c|}
\hline \multicolumn{3}{|c|}{ Dependent variables } \\
\hline 1 & Driving & $\begin{array}{l}\text { The percentage of people in each } \\
\text { census block group who chose to } \\
\text { drive to work }\end{array}$ \\
\hline 2 & Walking & $\begin{array}{l}\text { Percentage of people in each } \\
\text { census block group who chose to } \\
\text { walk to work }\end{array}$ \\
\hline 3 & Bicycling & $\begin{array}{l}\text { Percentage of people in each } \\
\text { census block group who chose to } \\
\text { ride a bicycle to work }\end{array}$ \\
\hline 4 & Public Transport & $\begin{array}{l}\text { Percentage of people in each } \\
\text { census block group who chose to } \\
\text { ride public transport to work }\end{array}$ \\
\hline
\end{tabular}

\begin{tabular}{|c|c|c|}
\hline \multicolumn{3}{|c|}{ Independent Variables } \\
\hline \multicolumn{3}{|c|}{ Land Use Variables } \\
\hline 1 & Population Density & $\begin{array}{l}\text { Number of people per acre of } \\
\text { each census block group }\end{array}$ \\
\hline 2 & Street Density & $\begin{array}{l}\text { Total length of streets (mile) } \\
\text { divided by the area of census } \\
\text { block group (Sq. mile) }\end{array}$ \\
\hline 3 & Commercial Density & $\begin{array}{l}\text { Area of commercial parcels (Sq. } \\
\text { Mile) divided by the area of } \\
\text { census block-group (Sq. mile) }\end{array}$ \\
\hline 4 & Building Density & $\begin{array}{l}\text { Sum of figure-ground of all } \\
\text { buildings in a block group } \\
\text { divided by the area of } \\
\text { corresponding block group }\end{array}$ \\
\hline 5 & Age of Buildings & $\begin{array}{l}\text { The median age of buildings in } \\
\text { each block group }\end{array}$ \\
\hline 6 & Rental Vacancy Rate & $\begin{array}{l}\text { Percentage of vacant houses for } \\
\text { designated for rent }\end{array}$ \\
\hline 7 & Number of Rooms & $\begin{array}{l}\text { Median number of rooms of } \\
\text { residential buildings in each } \\
\text { block group }\end{array}$ \\
\hline \multicolumn{3}{|c|}{ Transportation Variables } \\
\hline 8 & Distance to PTS & $\begin{array}{l}\text { Average distance of residential } \\
\text { buildings to the nearest public } \\
\text { transport stations or stops }\end{array}$ \\
\hline 9 & Travel Time & $\begin{array}{l}\text { Average travel time of journeys } \\
\text { to work }\end{array}$ \\
\hline 10 & Car Ownership & $\begin{array}{l}\text { Median number of vehicles per } \\
\text { person }\end{array}$ \\
\hline \multicolumn{3}{|c|}{ Socio-economic and Demographic Variables } \\
\hline 11 & Race Black & $\begin{array}{l}\text { Percentage of Black population } \\
\text { in each census block group }\end{array}$ \\
\hline 12 & Race White & $\begin{array}{l}\text { Percentage of White population } \\
\text { in each census block group }\end{array}$ \\
\hline
\end{tabular}

$\begin{array}{|lll|}13 & \text { Hispanic } & \begin{array}{l}\text { Percentage of Hispanic } \\ \text { population in each census block } \\ \text { group }\end{array} \\ & \begin{array}{l}\text { Percentage of family households } \\ \text { in each census block group } \\ \text { (family household is defined as }\end{array} \\ & \text { Family Households } & \begin{array}{l}\text { a householder and one or more } \\ \text { other people related to the } \\ \text { householder by birth, marriage }\end{array} \\ & \text { or adoption) }\end{array}$


attributes and six are space syntax variables (see table 2 above). This study aimed to understand the effects of large number of variables on the choice of four transport modes that people made to their journeys between home and work places: driving, riding public transportation, bicycling, and walking. To that end, several statistical analyses were performed to select the best models for each transport mode. Since large datasets were considered, the research began with a collinearity diagnostic test to detect multicollinearity problems between the independent variables. The observed collinearity was not similar in all cities; however, the common collinearities were due to the strong correlations between racial identity (Caucasian versus AfricanAmerican), ownership type (homeowners versus renters), and the two integration variables (topological and angular integration). Examining the collinearity test among the space syntax variables, particularly the integration values computed in two methods, very higher degree of collinearity was observed because of their strong correlation. Figure 15 illustrates the strong correlation between angular and topological integration variables.

After a repeated variance inflation factor (VIF) analysis (eliminating one variables with higher VIF value at a time), forward regression analysis was performed using SPSS statistical software to select the best model in relation to each of the four dependent variables. Four multiple regressions analysis (one for each transport mode) were performed in each city and a model for each dependent variable was selected with sets of significant independent variables (see tables 3-6 below).
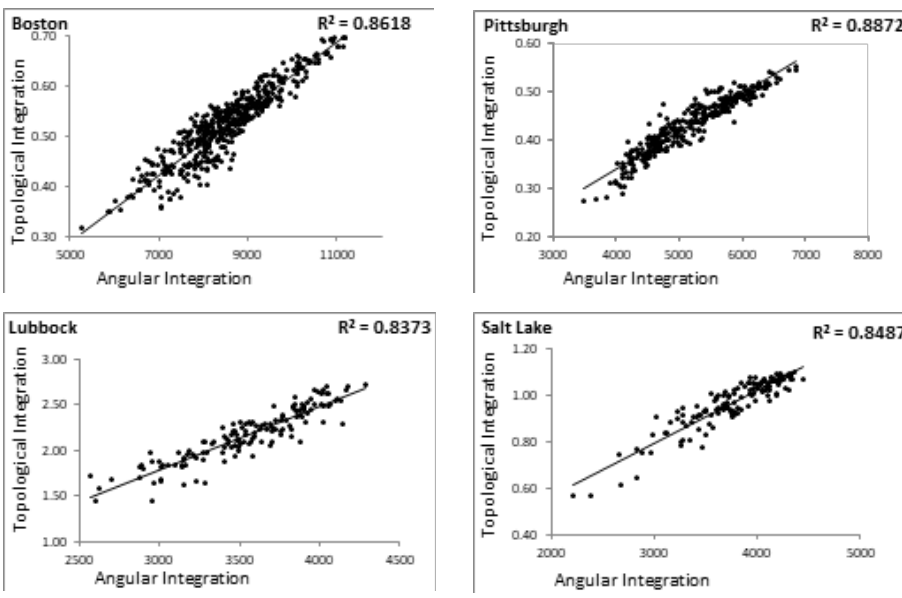

Figure 15. Correlation between topological and angular integrations values of all four cities

\section{RESULTS AND DISCUSSIONS}

As indicated earlier, this research has three goals. The first is to investigate whether space syntax is a significant tool to explain transport mode choices for journeys to work places among all other variables identified in previous researches on transport planning. Second is to investigate the possible variance between the configuration (syntactic) properties of gridded and non-gridded cities. Finally, the study aims to examine the effect of configuration on residential location choices in relation to work locations. To answer these research questions, multiple regression is employed producing a separate model for each transport mode (dependent variable). In addition, simple linear regressions are performed to examine the effect of configuration on land use pattern (commercial and retail concentration and building density).

\subsection{Effect of Configuration on Transport Mode Choices \\ 3.1.1 Driving Mode choice}

Table 3 summarizes the multiple linear regression analysis for driving mode choices. The adjusted R-square value of the model for driving are as follows: Boston (0.61), Pittsburgh (0.55), Lubbock (0.28), and Salt Lake City (0.61). The models contain some common variables, for instance, travel time is significant to explain driving mode choice in all cities while property value, car ownership, and percentage of family households were found to be significant in the models of three cities (Boston, Pittsburgh, and Salt Lake). Similarly, variables regarding socioeconomic and demographic attributes such as percentage of Asian population, household size, percentage of renters, and variables related to configuration, i.e. topological integration and choice each appeared twice out of the four models. Space Syntax variables were included in all four models. Among the Space Syntax variables, topological integration of axial lines was selected in models of Boston and Pittsburgh and topological choice of axial lines was included in the models of Lubbock and Salt Lake (see bold text in table 3). These disparities seem to group the cities into gridded and non-gridded.

The negative relationship between configuration variables and driving mode were found to be invariant in all cities. The negative coefficient suggests that keeping all other variables constant, people who live in topologically segregated neighborhoods of non-gridded cities (Boston and Pittsburgh) are more likely to drive to work locations than people living in integrated areas. Similarly, workers who live in neighborhoods with lower values of topological choice in gridded cities (Lubbock and Salt Lake City) are likely to choose driving than areas of higher choice values.

\subsubsection{Walking Mode choice}

Table 4 summarizes the results of multiple regression analysis for walking choice in the four cities. The models of walking obtained adjusted R2 of 0.61 in Boston, 0.50 in Pittsburgh, 0.26 in Lubbock, and 0.40 in Salt Lake City. The models for walking mode choice include some common significant variables. Car ownership and percentage of family household are negatively correlated to walking mode. Topological integration was selected among other variables that explain walking in the non-gridded cities (Boston and Pittsburgh) like the models of driving illustrated in section 3.1.1 above. Choice was included in models of gridded cities (Lubbock and Salt Lake City). A slight difference is observed in walking models in contrast to the driving models of gridded cities above. The difference is that angular choice is selected in Salt Lake City while topological choice in Lubbock. Once again, topological integration is among the top variables that obtain 0.00 P-values implying that space syntax is important in predicting walking mode in these particular cities. The positive coefficients of space syntax variables (integration in nongridded cities and choice in gridded cities) in all four cities implicate that all other variables being equal, choice of walking is determined by configurational values of integration and choice respectively. In other words, people who live in configurationally integrated areas of Boston and Pittsburgh or areas of higher choice values in Lubbock and Salt Lake City are likely to walk for their work trips proportional to the coefficients of integration or choice. 
Table 3. Multiple regression models for driving mode

BOSTON ---- $R^{2}=0.62$, Adj. $R^{2}=0.61$

\begin{tabular}{|c|c|c|c|c|c|c|}
\hline & Coefficients & Standard Error & t Stat & $P$-value & Lower 95\% & Upper 95\% \\
\hline Intercept & 0.54 & 0.09 & 6.09 & 0.00 & 0.36 & 0.71 \\
\hline Travel time & -0.004 & 0.00 & -3.74 & 0.00 & -0.01 & 0.00 \\
\hline Topological integration & -0.32 & 0.10 & -3.02 & 0.00 & -0.52 & -0.11 \\
\hline$\%$ of Hispanic population & -0.10 & 0.04 & -2.40 & 0.02 & -0.18 & -0.02 \\
\hline$\%$ of family households & 0.18 & 0.05 & 3.57 & 0.00 & 0.08 & 0.28 \\
\hline$\%$ of Renters & -0.16 & 0.04 & -3.84 & 0.00 & -0.24 & -0.08 \\
\hline Average household size & 0.04 & 0.02 & 2.47 & 0.01 & 0.01 & 0.08 \\
\hline Median number of rooms & 0.03 & 0.01 & 2.77 & 0.01 & 0.01 & 0.05 \\
\hline Car ownership & 0.28 & 0.03 & 10.68 & 0.00 & 0.23 & 0.34 \\
\hline Median gross rent & $-1 \mathrm{E}-04$ & 0.00 & -5.39 & 0.00 & 0.00 & 0.00 \\
\hline Median property value & $-9 \mathrm{E}-08$ & 0.00 & -1.99 & 0.047 & 0.00 & 0.00 \\
\hline Street density & $-7 E-04$ & 0.00 & -4.27 & 0.00 & 0.00 & 0.00 \\
\hline \multicolumn{7}{|c|}{ PITTSBURGH ---- $R^{2}=0.56, \mathrm{Adj} . \mathrm{R}^{2}=0.55$} \\
\hline & Coefficients & Standard Error & t Stat & P-value & Lower 95\% & Upper 95\% \\
\hline Intercept & 0.94 & 0.11 & 8.3 & 0.00 & 0.72 & 1.16 \\
\hline Travel time & -0.003 & 0 & -3.05 & 0.00 & -0.01 & 0 \\
\hline Topological integration & -1.01 & 0.18 & -5.59 & 0.00 & -1.37 & -0.66 \\
\hline$\%$ of White population & 0.07 & 0.03 & 2.19 & 0.03 & 0.01 & 0.13 \\
\hline$\%$ of Asian population & -0.23 & 0.11 & -2.16 & 0.03 & -0.45 & -0.02 \\
\hline$\%$ of family households & 0.17 & 0.06 & 2.91 & 0.00 & 0.06 & 0.29 \\
\hline Median household income & $1.6 \mathrm{E}-06$ & $5.3 \mathrm{E}-07$ & 3.06 & 0.00 & $6 \mathrm{E}-07$ & $2.7 \mathrm{E}-06$ \\
\hline$\%$ of renters & -0.15 & 0.05 & -2.99 & 0.00 & -0.25 & -0.05 \\
\hline Car ownership & 0.16 & 0.03 & 5.69 & 0.00 & 0.11 & 0.22 \\
\hline Median property value & $-5.00 \mathrm{E}-07$ & 0 & -4.6 & 0.00 & 0 & 0 \\
\hline \multicolumn{7}{|c|}{ LUBBOCK --- $R^{2}=0.30$, Adj. $R^{2}=0.28$} \\
\hline & Coefficients & Standard Error & t Stat & P-value & Lower 95\% & Upper 95\% \\
\hline Intercept & 107.31 & 3.35 & 32.03 & 0.00 & 100.68 & 113.93 \\
\hline Travel time & -0.56 & 0.17 & -3.27 & 0.00 & -0.9 & -0.22 \\
\hline Topological choice & $-1.50 \mathrm{E}-05$ & 0 & -2.92 & 0.00 & 0 & 0 \\
\hline$\%$ of Asian population & -0.53 & 0.15 & -3.6 & 0.00 & -0.83 & -0.24 \\
\hline Rental vacancy rate & -0.66 & 0.12 & -5.33 & 0.00 & -0.91 & -0.42 \\
\hline
\end{tabular}


SALT LAKE CITY ---- $R^{2}=0.64$, Adj. $R^{2}=0.61$

\begin{tabular}{|c|c|c|c|c|c|c|}
\hline & Coefficients & Standard Error & t Stat & P-value & Lower 95\% & Upper 95\% \\
\hline Intercept & 55.46 & 9.62 & 5.77 & 0.00 & 36.43 & 74.48 \\
\hline Travel time & -0.81 & 0.25 & -3.25 & 0.00 & -1.31 & -0.32 \\
\hline Topological choice & $-2.20 \mathrm{E}-06$ & 0 & -2 & 0.047 & 0 & 0 \\
\hline Distance to PTS & 0.01 & 0 & 4.11 & 0.00 & 0 & 0.01 \\
\hline Car ownership & 15.49 & 3.43 & 4.52 & 0.00 & 8.71 & 22.27 \\
\hline$\%$ of family households & 0.26 & 0.07 & 3.51 & 0.00 & 0.11 & 0.4 \\
\hline Average household size & 6.38 & 2.16 & 2.96 & 0.00 & 2.11 & 10.66 \\
\hline Median property value & $-4.10 \mathrm{E}-05$ & 0 & -5.42 & 0.00 & 0 & 0 \\
\hline
\end{tabular}

Table 4. Multiple regression models for walking mode

BOSTON --- $R^{2}=0.62$, Adj. $R^{2}=0.61$

$\begin{array}{rrrrrr}\text { Coefficients } & \text { Standard Error } & t \text { Stat } & \text { P-value } & \text { Lower 95\% } & \text { Upper 95\% } \\ 0.18 & 0.08 & 2.33 & 0.02 & 0.03 & 0.33 \\ -0.01 & 0 & -6.24 & 0.00 & -0.01 & 0 \\ 0.63 & 0.09 & 7.06 & 0.00 & 0.45 & 0.81 \\ -0.04 & 0.01 & -2.82 & 0.00 & -0.06 & -0.01 \\ -0.02 & 0.01 & -2.42 & 0.02 & -0.04 & 0 \\ -0.001 & 0 & -2.01 & 0.04 & 0 & 0 \\ -0.13 & 0.02 & -5.65 & 0.00 & -0.18 & -0.09 \\ 4.00 \mathrm{E}-05 & 0 & 2.92 & 0.00 & 0 & 0 \\ 2.00 \mathrm{E}-07 & 0 & 4.17 & 0.00 & 0 & 0 \\ 0.1 & 0.04 & 2.46 & 0.01 & 0.02 & 0.17 \\ 0.19 & 0.07 & 2.57 & 0.01 & 0.04 & 0.33\end{array}$

PITTSBURGH ---- $R^{2}=0.51$, Adj. $R^{2}=0.50$

Intercept
Travel time
Topological integration
\% of Asian population
\% Family households
Median household income
Average household size
Car ownership
Median property value
Commercial density

$\begin{array}{rrrrrr}\text { Coefficients } & \text { Standard Error } & t \text { Stat } & \text { P-value } & \text { Lower 95\% } & \text { Upper 95\% } \\ -0.01 & 0.08 & -0.1 & 0.92 & -0.17 & 0.15 \\ -0.004 & 0 & -5.02 & 0.00 & -0.01 & 0 \\ 0.45 & 0.11 & 4.13 & 0.00 & 0.23 & 0.66 \\ 0.2 & 0.08 & 2.61 & 0.01 & 0.05 & 0.35 \\ -0.24 & 0.05 & -5.22 & 0.00 & -0.33 & -0.15 \\ -1.20 \mathrm{E}-06 & 0 & -3.33 & 0.00 & 0 \\ 0.07 & 0.02 & 3.95 & 0.00 & 0.04 & 0.11 \\ -0.04 & 0.02 & -2.12 & 0.03 & -0.08 & 0 \\ 3.70 \mathrm{E}-07 & 0 & 4.64 & 0.00 & 0 & 0 \\ 0.23 & 0.07 & 3.54 & 0.00 & 0.1 & 0.36\end{array}$




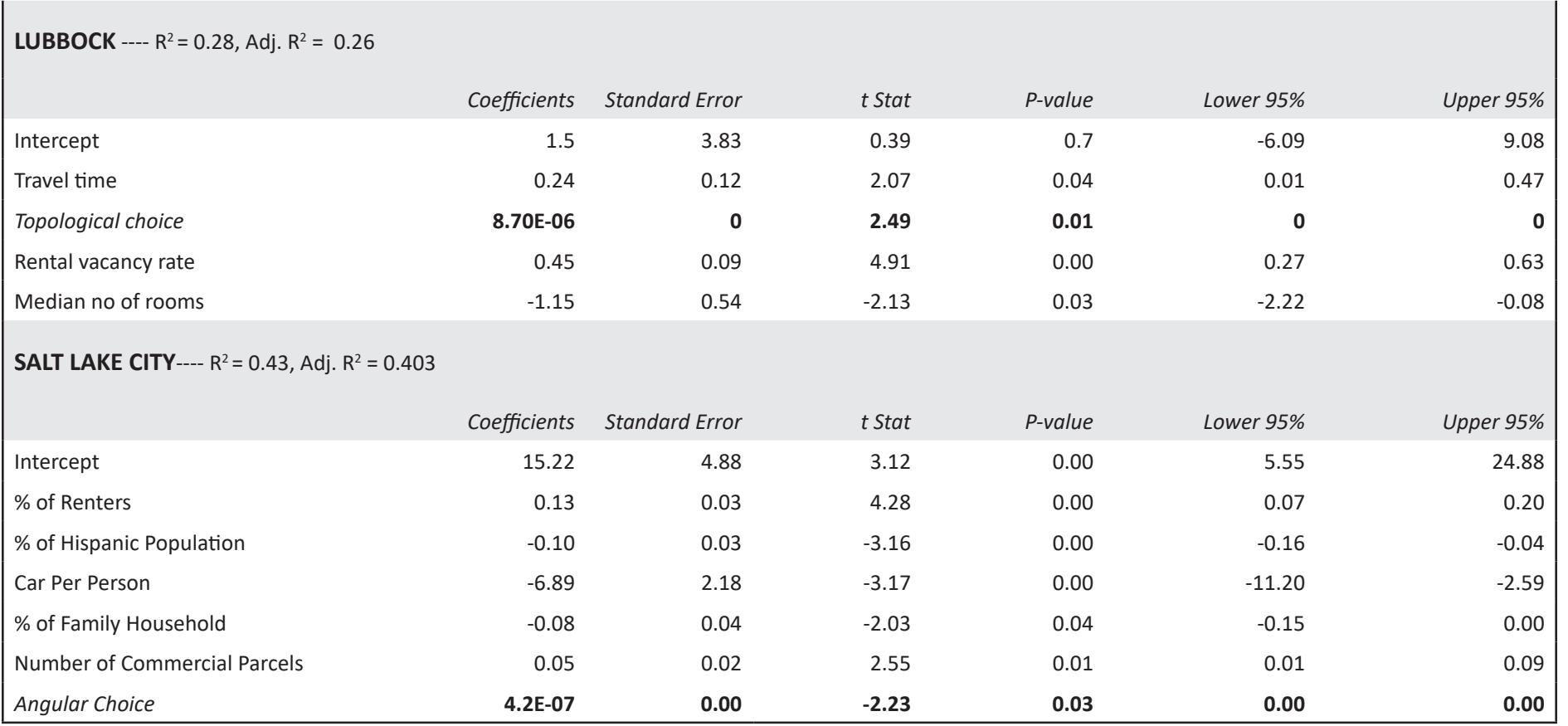

Table 5. Multiple regression models for public transport mode

\begin{tabular}{|c|c|c|c|c|c|c|}
\hline & Coefficients & Standard Error & $t$ Stat & $P$-value & Lower 95\% & Upper 95\% \\
\hline Intercept & 0.12 & 0.05 & 2.35 & 0.02 & 0.02 & 0.22 \\
\hline Travel time & 0.01 & 0 & 10.76 & 0.00 & 0.01 & 0.01 \\
\hline Distance to PTS & $-3.0 \mathrm{E}-04$ & 0 & -3.44 & 0.00 & 0 & 0 \\
\hline$\%$ of Hispanic population & 0.13 & 0.04 & 3.48 & 0.00 & 0.06 & 0.21 \\
\hline$\%$ of Family household & -0.16 & 0.04 & -4.52 & 0.00 & -0.23 & -0.09 \\
\hline$\%$ of Renters & 0.16 & 0.04 & 4.57 & 0.00 & 0.09 & 0.23 \\
\hline Rental vacancy rate & 0.43 & 0.11 & 3.8 & 0.00 & 0.21 & 0.66 \\
\hline Car ownership & -0.1 & 0.02 & -4.43 & 0.00 & -0.15 & -0.06 \\
\hline Commercial density & -0.09 & 0.04 & -2.36 & 0.02 & -0.17 & -0.02 \\
\hline \multicolumn{7}{|c|}{ PITTSBURGH ---- R Square $=0.51, \mathrm{Adj} . \mathrm{R}^{2}=0.50$} \\
\hline & Coefficients & Standard Error & $t$ Stat & P-value & Lower 95\% & Upper 95\% \\
\hline Intercept & 0.12 & 0.07 & 1.78 & 0.08 & -0.01 & 0.25 \\
\hline Travel time & 0.01 & 0 & 8.21 & 0.00 & 0.01 & 0.01 \\
\hline$\%$ of White population & -0.19 & 0.02 & -8.59 & 0.00 & -0.23 & -0.15 \\
\hline$\%$ of renters & 0.19 & 0.03 & 6.08 & 0.00 & 0.13 & 0.25 \\
\hline Average household size & -0.04 & 0.02 & -2.47 & 0.01 & -0.07 & -0.01 \\
\hline Median building age & 0.001 & 0 & 2.45 & 0.01 & 0 & 0 \\
\hline Car ownership & -0.05 & 0.02 & -2.55 & 0.01 & -0.09 & -0.01 \\
\hline
\end{tabular}




\begin{tabular}{|c|c|c|c|c|c|c|}
\hline \multicolumn{7}{|c|}{ LUBBOCK --- $R^{2}=0.27$, Adj. $R^{2}=0.25$} \\
\hline & Coefficients & Standard Error & t Stat & $P$-value & Lower 95\% & Upper 95\% \\
\hline Intercept & 3.14 & 1.51 & 2.08 & 0.04 & 0.15 & 6.13 \\
\hline Car ownership & -2.35 & 1.05 & -2.23 & 0.03 & -4.43 & -0.26 \\
\hline$\%$ of Black population & 0.07 & 0.02 & 4.07 & 0.00 & 0.04 & 0.11 \\
\hline$\%$ of Asian Population & 0.35 & 0.07 & 5.34 & 0.00 & 0.22 & 0.49 \\
\hline \multicolumn{7}{|c|}{ SALT LAKE CITY---- R Square $=0.58, \mathrm{Adj} . \mathrm{R}^{2}=0.55$} \\
\hline & Coefficients & Standard Error & t Stat & $P$-value & Lower 95\% & Upper $95 \%$ \\
\hline Intercept & 6.14 & 4.9 & 1.25 & 0.21 & -3.56 & 15.85 \\
\hline$\%$ of Asian population & 0.23 & 0.11 & 2.02 & 0.046 & 0 & 0.45 \\
\hline Travel time & 0.67 & 0.14 & 4.86 & 0.00 & 0.4 & 0.95 \\
\hline Car ownership & -4.9 & 1.98 & -2.47 & 0.02 & -8.82 & -0.97 \\
\hline$\%$ of family household & -0.18 & 0.03 & -5.66 & 0.00 & -0.25 & -0.12 \\
\hline Median gross rent & -0.01 & 0 & -2.63 & 0.01 & -0.01 & 0 \\
\hline Median property value & $1.80 \mathrm{E}-05$ & 0 & 3.77 & 0.00 & 0 & 0 \\
\hline Population density & 0.14 & 0.06 & 2.48 & 0.01 & 0.03 & 0.26 \\
\hline
\end{tabular}

Table 6. Multiple regression models for bicycling mode

\begin{tabular}{|c|c|c|c|c|c|c|}
\hline \multicolumn{7}{|c|}{ BOSTON --- R Square = 0.06, Adj. $R^{2}=0.05$} \\
\hline & Coefficients & Standard Error & t Stat & P-value & Lower 95\% & Upper 95\% \\
\hline Intercept & 0.02 & 0.01 & 2.62 & 0.01 & 0 & 0.03 \\
\hline$\%$ of Black population & -0.01 & 0.01 & -2.33 & 0.02 & -0.03 & 0 \\
\hline$\%$ of family households & -0.04 & 0.01 & -3.68 & 0.00 & -0.07 & -0.02 \\
\hline Average household size & 0.01 & 0 & 2.56 & 0.01 & 0 & 0.02 \\
\hline \multicolumn{7}{|c|}{ PITTSBURGH ---- R Square $0.14, \mathrm{Adj} . \mathrm{R}^{2}=0.135$} \\
\hline & Coefficients & Standard Error & t Stat & P-value & Lower 95\% & Upper 95\% \\
\hline Intercept & -0.06 & 0.01 & -5.86 & 0.00 & -0.08 & -0.04 \\
\hline$\%$ of White population & 0.02 & 0 & 4.82 & 0.00 & 0.01 & 0.03 \\
\hline Topological integration & 0.13 & 0.02 & 6.2 & 0.00 & 0.09 & 0.17 \\
\hline \multicolumn{7}{|c|}{ LUBBOCK ---- $R^{2}=0.18$, Adj. $R^{2}=0.16$} \\
\hline & Coefficients & Standard Error & t Stat & P-value & Lower 95\% & Upper 95\% \\
\hline Intercept & 2.65 & 0.66 & 4.02 & 0.00 & 1.35 & 3.95 \\
\hline$\%$ of family households & -0.04 & 0.01 & -4.41 & 0.00 & -0.06 & -0.02 \\
\hline Topological choice & 3.30E-06 & 0 & 2.6 & 0.01 & 0 & 0 \\
\hline \multicolumn{7}{|c|}{ SALT LAKE CITY --- $R^{2}=0.14$, Adj. $R^{2}=0.13$} \\
\hline & Coefficients & Standard Error & t Stat & P-value & Lower 95\% & Upper 95\% \\
\hline Intercept & 4.72 & 1.01 & 4.66 & 0.00 & 2.72 & 6.72 \\
\hline Average household size & -1.81 & 0.39 & -4.58 & 0.00 & -2.59 & -1.03 \\
\hline Median gross rent & 0.003 & 0 & 2.2 & 0.03 & 0 & 0 \\
\hline
\end{tabular}




\subsubsection{Public Transport Mode choice}

Table 5 summarizes the multiple linear regression of public transport mode choices and shows that space syntax variables were not significant. Car ownership is consistently important in all cities and correlates negatively with public transport. This implies that areas with lower number of cars per person are likely to have more public transportation riders to work places. In fact, car ownership is an important factor affecting the choice of walking and driving in all cities except Lubbock.

Percentage of renters are observed to be significant in models of public transportation for non-gridded cities (Boston and Pittsburgh) suggesting renters opt to ride public transport more than homeowners in these two cities. Family households prefer driving than riding public transport. Our assumption for this is probably because driving would be more convenient than other modes of transport for family households, especially for those who have children. The distance to public transport stations was only significant in Boston.

Table 7. Summary of space syntax variables selected in each regression model

\begin{tabular}{|c|c|c|c|c|}
\hline $\begin{array}{l}\text { Transport } \\
\text { Mode }\end{array}$ & Boston & Pittsburgh & Lubbock & Salt Lake City \\
\hline Driving & $\begin{array}{l}\text { Topological } \\
\text { Integration } \\
\text { (-ve) }\end{array}$ & $\begin{array}{c}\text { Topological } \\
\text { Integration } \\
\text { (-ve) }\end{array}$ & $\begin{array}{l}\text { Topological } \\
\text { Choice (-ve) }\end{array}$ & $\begin{array}{l}\text { Topological } \\
\text { Choice (-ve) }\end{array}$ \\
\hline Walking & $\begin{array}{l}\text { Topological } \\
\text { Integration } \\
\text { (+ve) }\end{array}$ & $\begin{array}{l}\text { Topological } \\
\text { Integration } \\
\text { (+ve) }\end{array}$ & $\begin{array}{l}\text { Topological } \\
\text { Choice (+ve) }\end{array}$ & $\begin{array}{c}\text { Angular } \\
\text { Choice (+ve) }\end{array}$ \\
\hline \multicolumn{5}{|l|}{$\begin{array}{l}\text { Public } \\
\text { Transport }\end{array}$} \\
\hline Bicycling & & $\begin{array}{c}\text { Topological } \\
\text { Integration } \\
\text { (+ve) }\end{array}$ & $\begin{array}{l}\text { Topological } \\
\text { Choice (+ve) }\end{array}$ & \\
\hline
\end{tabular}
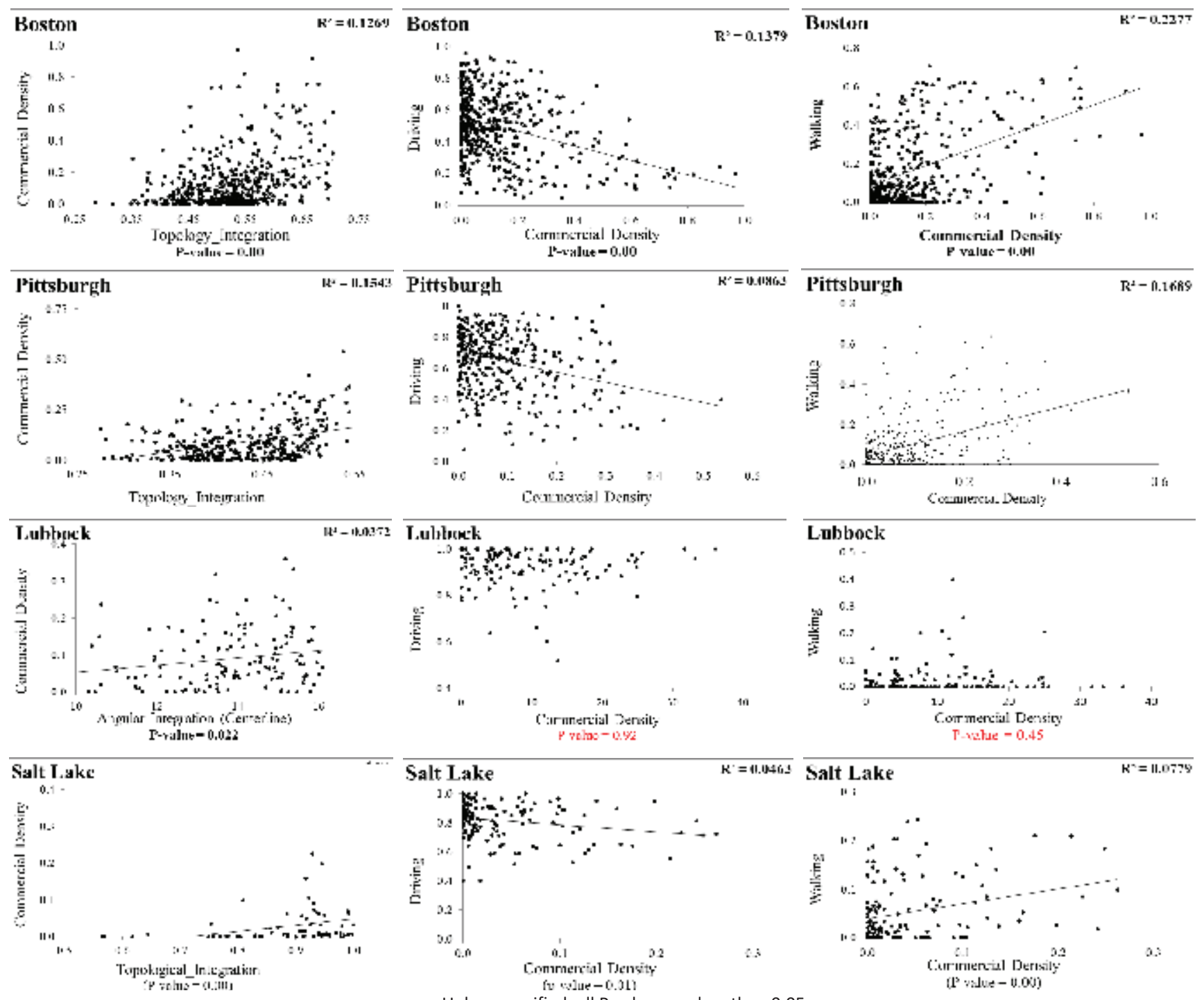

Unless specified, all P-values are less than 0.05

Figure 16. Relationship of commercial density with integration, driving, and walking 

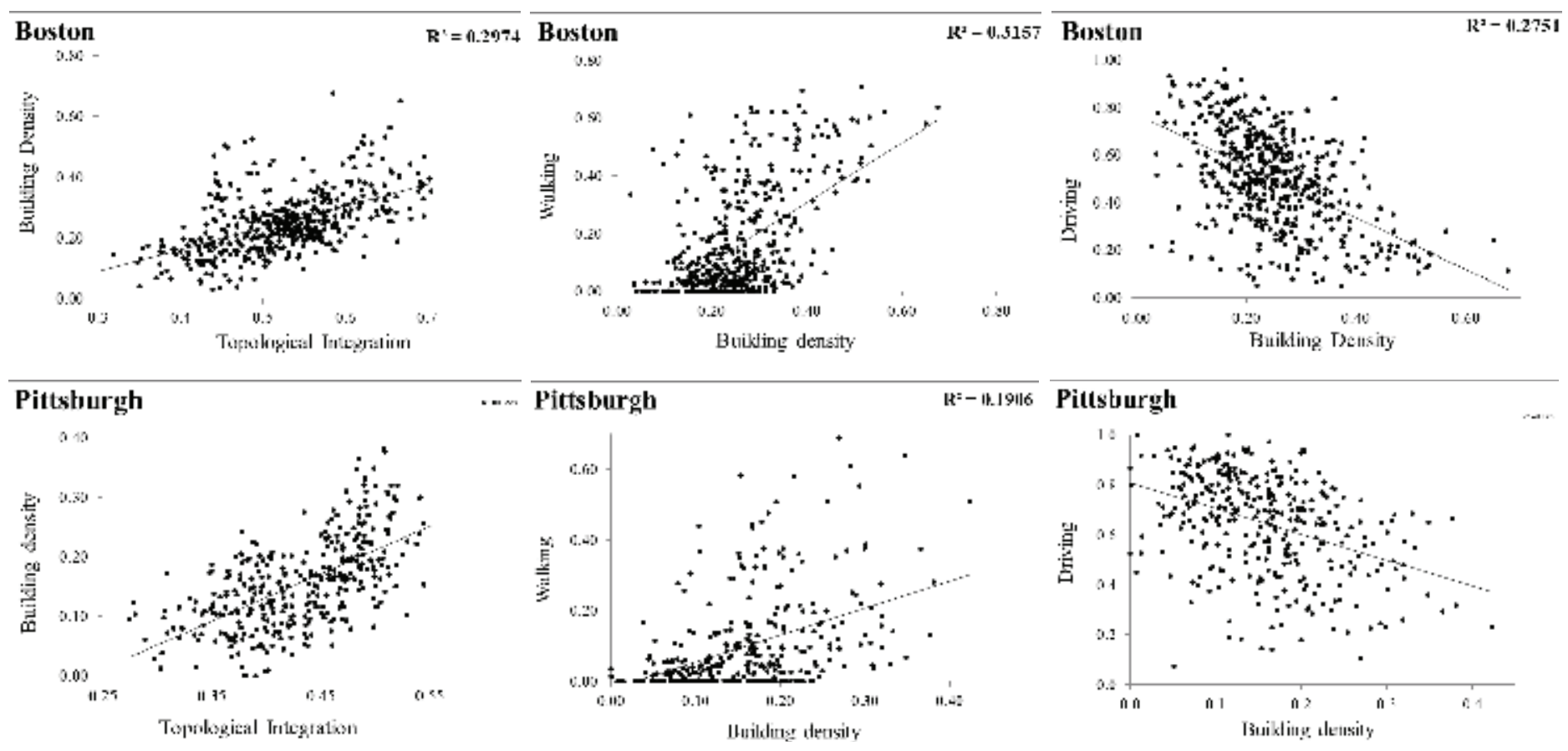

\section{Pittsburgh}
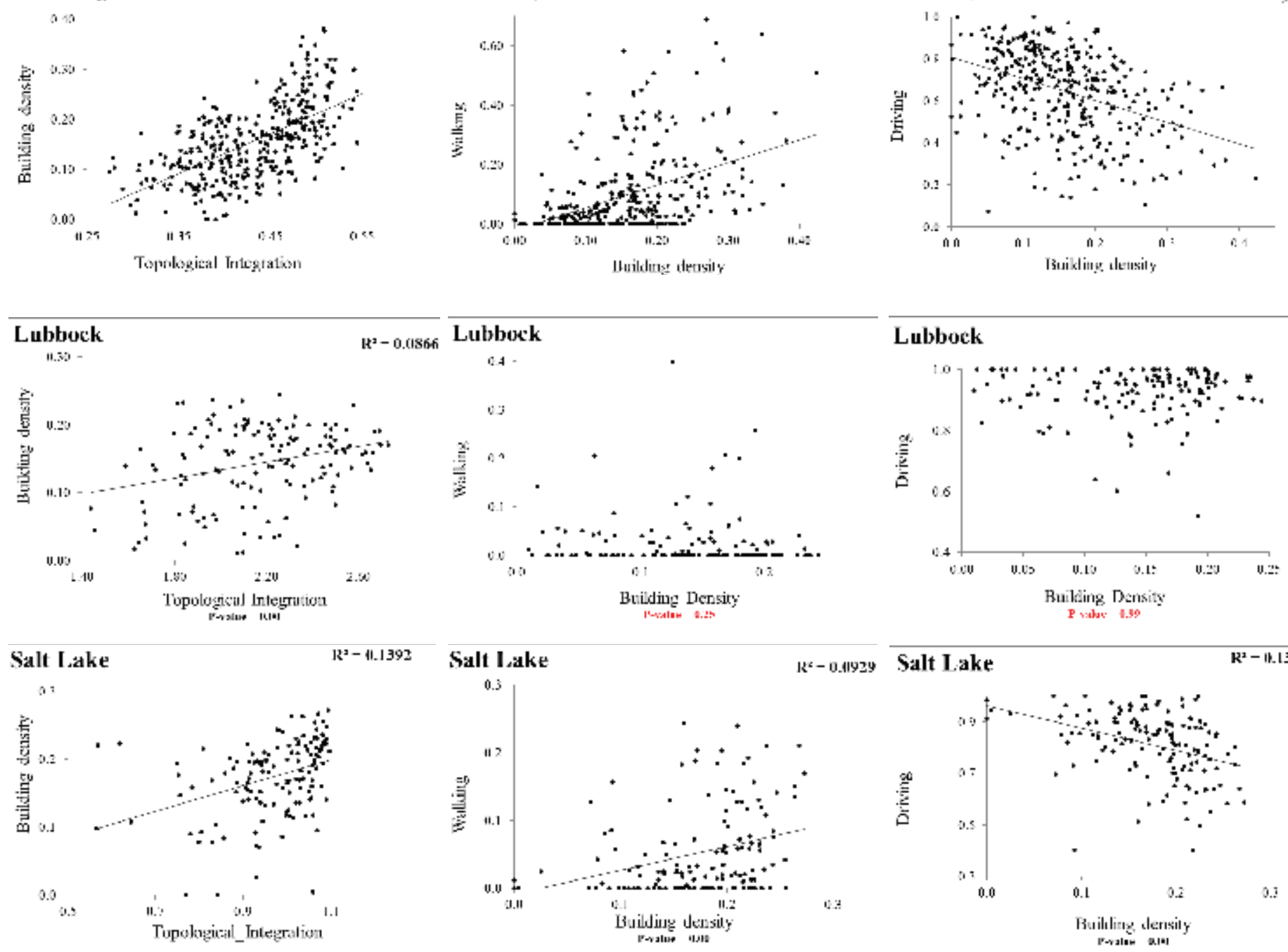

Figure 17. Relations of building density with integration, walking and driving 

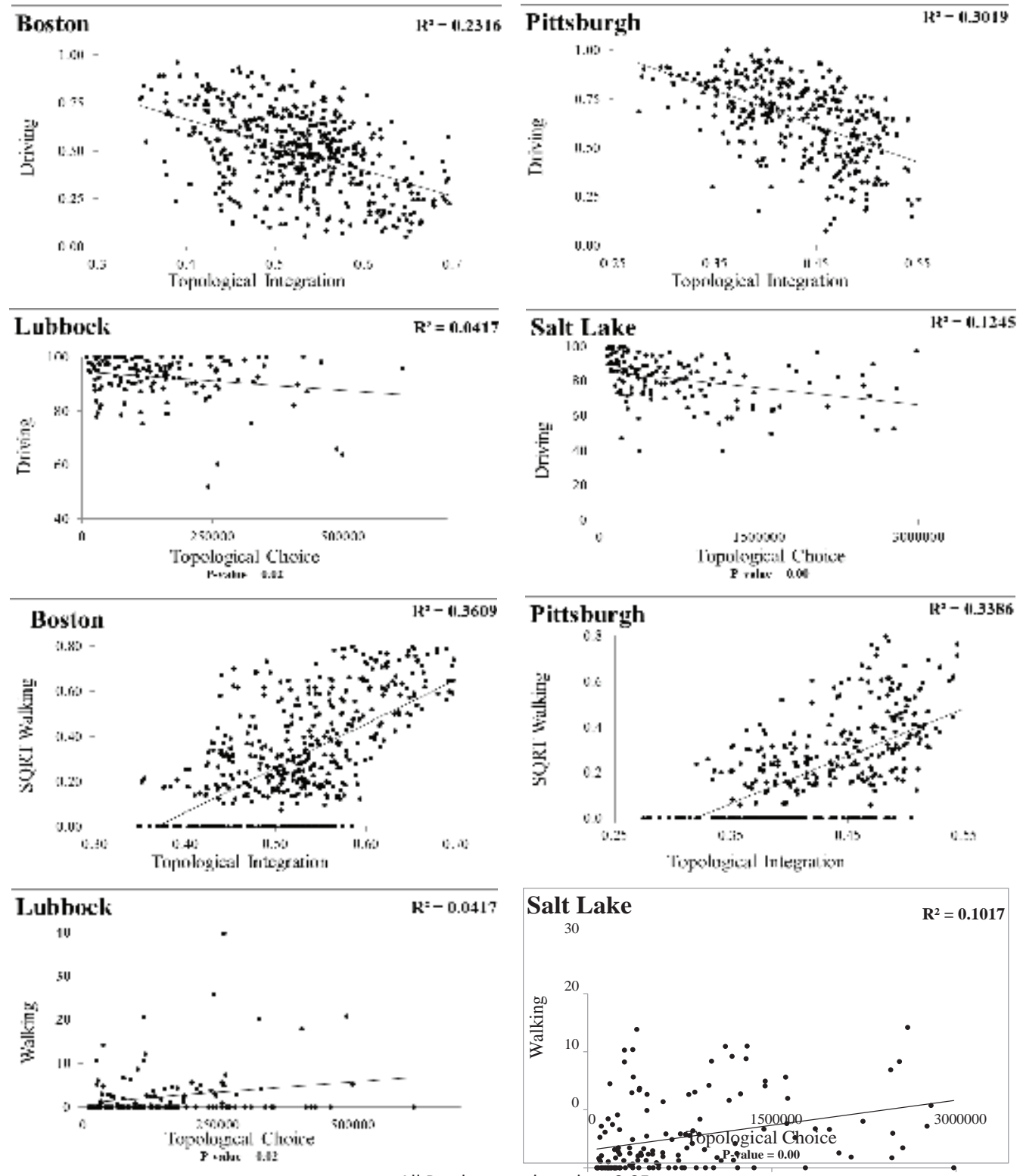

Figure 18. Scatterplot of integration vs driving and walking

\subsubsection{Bicycling Mode choice}

Models of bicycling are weak in all cities compared to the other three modes of transport (see Table 6). The adjusted $\mathrm{R}$ square values are 0.05 for Boston, 0.14 for Pittsburgh, 0.16 for Lubbock and 0.13 for Salt Lake City. This means the models can explain bicycling only $5 \%$ in Boston, $14 \%$ in Pittsburgh, $16 \%$ in Lubbock and $13 \%$ in Salt Lake City. The maximum numbers of variables selected are three in Boston. Moreover, except family household which is selected in both Boston and Lubbock, the models did not share common variables, and have fewer number of variables compared to other models.
When we look at the summary in table 7 below, integration is relevant for non-gridded cities (Boston and Pittsburgh) and choice is for gridded cities (Lubbock and Salt Lake City). Both space syntax variables are also negatively related to driving whereas positively with walking and bicycling. This implies that configurationally integrated areas of nongridded cities of Boston and Pittsburgh or areas with higher choice values of gridded cities of Lubbock and Salt Lake City are more suitable for walking and bicycling than segregated areas or lower choice values. In parallel, segregated areas of Boston and Pittsburgh or areas with lower choice values of Lubbock and Salt Lake City are vulnerable for auto 
dependency.

\subsection{Configuration and Land-use 3.2.1 Configuration and Commercial density}

Despite weak power, configuration and commercial density have statistically significant relationship with integration and the two transport modes (driving and walking) in all cities except Lubbock. The positive relationships between commercial density and topological integration (see Figure 16) suggests that commercial land use is more concentrated in integrated neighborhoods. The study also examined whether commercial density has significant relationships with driving and walking modes. The result indicates that people who live in proximity to commercial concentrations are likely to walk more and drive less. Residents of configurationally segregated areas which are detached from commercial and retail concentrations are prone to drive.

\subsubsection{Configuration, Density and Transport mode}

Commercial density and building density displayed positive correlation with integration and walking, and negative correlation with driving in all cities except Lubbock where there were no statistically significant relationships (Figure 17). These relationships generally infer that renters are located at higher density neighborhoods, and this may be why they choose to walk more and drive less to work places. This also supports the new urbanism and smart growth movement's claim that density is one major instrument to achieve walkable urban environment (Brownstone and Golob 2009; Cervero and Kockelman 1997; Chen, Gong, and Paaswell 2007).

Even though we consistently observed integration influencing building density in all cities, the significant relationship of density with residential location and transport mode choice observed in Boston, Pittsburgh and Salt Lake City was not confirmed in Lubbock.

\subsubsection{Configuration Vs Walking and Driving}

Driving and walking are related to integration in all cities but opposite relationships. Figure 18 depicts that driving mode is consistently favored in segregated areas in all four cities while walking is preferred in integrated areas. However, these relationships have a tendency to be stronger in non-gridded cities and weaker in gridded cities.

\section{CONCLUSIONS}

The multiple regression analysis revealed that beside the variables identified in previous studies of transport planning, space syntax variables play a significant role in explaining travel behavior particularly in choices of driving and walking. Clearly, Space Syntax variables play a significant role in modelling walking and driving to work as was demonstrated by the inclusive methodology employed in this article. Furthermore, it is observed that people living in segregated areas of non-gridded cities and areas with less choice values in gridded cities preferred to drive to work. In contrast, people living in integrated areas (in non-gridded cities) and areas with higher choice values (in gridded cities) preferred to walk.

The scatterplots of simple linear regression analysis shown in figures 16 to 18 depicted the presence of positive relationship between configuration and commercial density. This infers retail and commercial areas are located in more integrated areas (though not confirmed in Lubbock). People who live in close proximity to retail and commercial concentration areas likely prefer walking to their work places. On the other hand, residents that are spatially detached from the areas of commercial and retail concentrations are prone to driving.
Variations are observed between gridded and non-gridded cities in selecting configuration variables particularly for driving and waking models. Integration was relevant for non-gridded cities while choice was for gridded ones. In other words, topological integration of streets was significant for driving and walking models in Pittsburgh and Boston (nongridded cities). On the other hand, driving mode selected topological choice in both Lubbock and Salt Lake City (gridded cities). It should be noted that integration and choice are positively correlated with walking, but negatively correlated with driving to work. When it comes to public transportation mode, no Space Syntax variable was found to be significant in all cities. 


\section{REFERENCES}

Berhie, G., \& Haq, S. (2015). The effect of spatial configuration on propensity for non-motorised journey to work: Case study of a gridded and non gridded American city. The 10th International Space Syntax Symposium , 062 (pp. 1-15). London.

Berhie, G., \& Haq, S. (2017). Locational preferences and transportation mode choice of different socio-economic groups in the US: a space syntax included case study of two gridded and two nongridded cities. The 11th International Space Syntax Symposium , 045 (pp. 1-21). Lisbon

Brownstone, David, and Thomas F. Golob. 2009. "The Impact of Residential Density on Vehicle Usage and Energy Consumption." Journal of Urban Economics 65 (1). Elsevier Inc.:91-98.

Cervero, Robert. 2002. "Built Environments and Mode Choice: Toward a Normative Framework." Transportation Research Part D: Transport and Environment 7 (4):265-84. https://doi. org/10.1016/S1361-9209(01)00024-4

Cervero, Robert, and Kara Kockelman. 1997. "Travel Demand and the 3D's: Density, Diversity, and Design." Transportation Research Part D: Transport and Environment, 199-219.

Charalambous, Nadia, and Magda Mavridou. 2012. "Space Syntax: Spatial Integration Accessibility and Angular Segment Analysis by Metric Distance (ASAMeD)." Accessibilityplanning.eu, 57-62.

Chen, Cynthia, Hongmian Gong, and Robert Paaswell. 2007. "Role of the Built Environment on Mode Choice Decisions: Additional Evidence on the Impact of Density." Transportation 35 (3):28599. https://doi.org/10.1007/s11116-007-9153-5

City of Boston. 2014. "BostonMaps: Open Data." 2014. http:// bostonopendata.boston.opendata.arcgis.com.

City of Lubbock. 2016. "GIS and Data Services." 2016. https://www. ci.lubbock.tx.us/departmental-websites/departments/gis-dataservices/home.

City of Pittsburgh Department of City Planning. 2016. "Geographic Information Systems." 2016. http://pittsburghpa.gov/dcp/gis/ gis-data-new.

Courtat, Thomas, Stéphane Douady, and Catherine Gloaguen. 2011. "Centrality Maps and the Analysis of City Street Networks." Proceedings of the 5th International ICST Conference on Performance Evaluation Methodologies and Tools, 316-21.

EPA. 2015. "United States Environmental Protection Agency." Http:// www.epa.gov/. 2015. https://www3.epa.gov/carbon-footprintcalculator.

Freeman, LC, SP Borgatti, and DR White. 1991. "Centrality in Valued Graphs: A Measure of Betweenness Based on Network Flow." Social Networks 13 (2):141-54. https://doi.org/10.1016/0378-

\section{3(91)90017-N}

Freeman, Linton C. 1977. "A Set of Measures of Centrality Based on Betweenness." Sociometry 40 (1):35-41. https://doi. org $/ 10.2307 / 3033543$

Giuliano, Genevieve. 2004. "Land Use Impacts of Transportation Investments - Highway and Transit." The Geography of Rban Transportation.

Haq, Saif. 2003. "Investigating the Syntax Line : Configurational Properties and Cognitive Correlates." Environment and Planning B: Planning and Design 30:841-63. https://doi.org/10.1068/ b2960

Hillier, Bill. 1996. "Cities as Movement Economies." Urban Design International 1 (1):41-60. https://doi.org/10.1057/udi.1996.5

Hillier, Bill. 1999a. "Centrality as a Process: Accounting for Attraction Inequalities in Deformed Grids." Urban Design International, 06.1-06.20.

Hillier, Bill. 1999b. "The Hidden Geometry of Deformed Grids: Or, Why Space Syntax Works, When It Looks as Though It Shouldn't." Environment and Planning B: Planning and Design 26:169-92.

Hillier, Bill. 2008. Space Is the Machine, (Chinese Translation). London: University of Cambridge. http://eprints.ucl.ac.uk/3881.

Hillier, Bill, and Julienne Hanson. 1984. The Social Logic of Space. Cambridge: Cambridge University Press.

Hillier, Bill, A. Penn, J. Hanson, T Grajewski, and J Xu. 1993. "Natural Movement-Or, Configuration and Attraction in Urban Pedestrian Movement." Environ Plann B 20:29-66. https://doi.org/10.1068/ b200029

Hillier, Bill, Alasdair Turner, Tao Yang, and Tae-Park Hoon. 2007. "Metric and Topo-Geometric Properties of Urban Street Networks: Some Convergences, Divergences, and New Results." Proceedings of 6th International Space Syntax Symposium, Istanbul. Istanbul, 001:1-001:22.

Jones, M, and M Fanek. 1997. "Crime in the Urban Environment." Proceedings of 1st International Space Syntax Symposium, London.

Levine, Jonathan, and Lawrence D. Frank. 2006. "Transportation and Land-Use Preferences and Residents' Neighborhood Choices: The Sufficiency of Compact Development in the Atlanta Region." Transportation 34 (2):255-74. https://doi.org/10.1007/s11116006-9104-6

Narayanan, Shivaram. 2005. "The Betweenness Centrality Of Biological Networks A Study of Betweenness Centrality."

Newman, P. W G, and Jeffrey R. Kenworthy. 1996. "The Land UseTransport Connection: An Overview." Land Use Policy 13 (1):1- 
22. https://doi.org/10.1016/0264-8377(95)00027-5

Nubani, Linda, and Jean Wineman. 2005. "The Role of Space Syntax in Identifying the Relationship between Space and Crime." Proceedings of 5th International Space Syntax Symposium, Delft.

Penn, Alan, and Ben Croxford. 1997. "Effect of Street Grid Configuration on Kerbside Concetration of Vehicular Emissions." Proceedings of 1st International Space Syntax Symposium, London II (Urban Themes):27.1-27.10.

Peponis, J., C. Zimring, and Y. Kyung Choi. 1990. "Finding the Building in Wayfinding." Environment and Behavior 22 (5):555-90. https:// doi.org/10.1177/0013916590225001

Peponis, John, Hadjinikolau E., Livieratos C., and Fatouros D.A. 1989. "The Spatial Core of Urban Culture." Ekistics 334:43-55.

Plaut, Pnina O. 2005. "Non-Motorized Commuting in the US." Transportation Research Part D: Transport and Environment 10 (5):347-56. https://doi.org/10.1016/j.trd.2005.04.002

Porta, Sergio, Vito Latora, Fahui Wang, Emanuele Strano, Alessio Cardillo, Salvatore Scellato, Valentino lacoviello, and Roberto Messora. 2009. "Street Centrality and Densities of Retail and Services in Bologna, Italy." Environment and Planning B: Planning and Design 36 (3):450-65. https://doi.org/10.1068/b34098

Pucher, John, and Lewis Dijkstra. 2003. "Promoting Safe Walking and Cycling to Improve Public Health: Lessons From The Netherlands and Germany." American Journal of Public Health 93 (9):150916. https://doi.org/10.2105/AJPH.93.9.1509

Salt Lake City. 2015. "Salt Lake City GIS Open Data." 2015. http://gis. slcgov.opendata.arcgis.com/datasets.

Schwanen, Tim, and Patricia L. Mokhtarian. 2005. "What Affects Commute Mode Choice: Neighborhood Physical Structure or Preferences toward Neighborhoods?" Journal of Transport Geography 13 (1):83-99.

Topçu, M, K Topçu, and K Deniz. 2007. "Movement Economy Dependent on Urban Design." In Proceedings of 6th International Space Syntax Symposium, Istanbul. Istanbul.

US Census Bureau. 2015. "TIGER Products." 2015. https://www.census. gov/geo/maps-data/data/tiger.html.

Varoudis, Tasos, Kayvan Karimi, Stephen Law, Bill Hillier, and Alan Penn. 2013. "Space Syntax Angular Betweenness Centrality Revisited." Proceedings of 9th International Space Syntax Symposium, Seoul.

Wardman, Mark, Miles Tight, and Matthew Page. 2007. "Factors Influencing the Propensity to Cycle to Work." Transportation Research Part A: Policy and Practice 41 (4):339-59. https://doi. org/10.1016/j.tra.2006.09.011 